2007

\title{
Perspectives of School Nurse Vocational Satisfaction: A Qualitative Analysis
}

Shirley G. Smith

Cedarville University

Follow this and additional works at: http://digitalcommons.cedarville.edu/education theses

Part of the Education Commons, and the Nursing Commons

\section{Recommended Citation}

Smith, Shirley G., "Perspectives of School Nurse Vocational Satisfaction: A Qualitative Analysis" (2007). Master of Education Research

Theses. 17.

http://digitalcommons.cedarville.edu/education_theses/17 


\section{PERSPECTIVES OF SCHOOL NURSE VOCATIONAL SATISFACTION:}

\section{A QUALITATIVE ANALYSIS}

A thesis submitted in partial fulfillment of the requirements for the degree of Masters of Education

By

SHIRLEY GILBERT SMITH

BSN, Capital University, 1973

2007

Cedarville University 


\section{CEDARVILLE UNIVERSITY \\ SCHOOL OF GRADUATE STUDIES}

September 27, 2007

I HEREBY RECOMMEND THAT THE THESIS PREPARED UNDER MY SUERPVISION BY Shirley Gilbert Smith ENTITLED Perspectives of School Nurse Vocational Satisfaction: A Qualitative Analysis BE ACCEPTED IN PARTIAL FULFILLMENT OF THE REQUIREMENTS FOR THE DEGREE OF Master of Education.

$\frac{\text { Willian } \sum \text { William E. Brown, Ph.D. }}{\text { President }}$

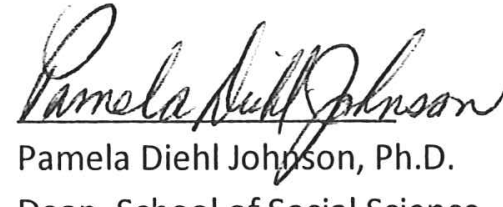

Dean, School of Social Science

And Human Performance

\section{Rovent Mellumen}

Robert W. Milliman, Ph.D. Academic Vice President

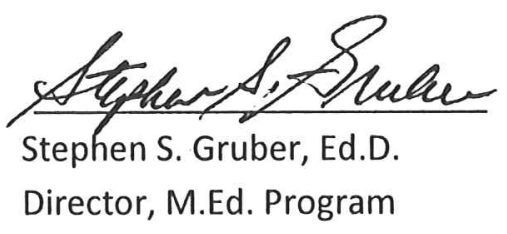

Michaelfin.

Michael W. Firmin, Ph.D.

Chair, Psychology Department

Thesis Advisor 


\begin{abstract}
Smith, Shirley G. M.Ed., Education Department, Cedarville University, 2007. Perspectives of School Nurse Vocational Satisfaction: A Qualitative Analysis.

This is a phenomenological, qualitative study of 25 school nurses employed in a large, urban school district in the Midwestern section of the United States. The study's participants possess histories of professional work experiences in nursing specialties other than school nursing. Given the wide range of potential nursing opportunities currently available to registered nurses with baccalaureate degrees, participants’ responses regarding their selection of school nursing as a career, their past and present job satisfaction levels in school nursing, challenges, success definitions, and the integration of work with home life all bring clarity to the participants' perspectives on this specialty of nursing. The insights of these school nurses assist in illuminating the personal and professional values of this cohort of school professionals.
\end{abstract}




\section{TABLE OF CONTENTS}

CHAPTER I: Introduction...................................................... 1

Definition of Terms.................................................... 10

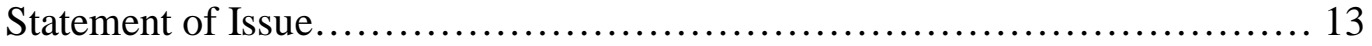

Scope of the Study and Delimitations.................................. 14

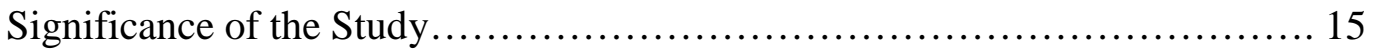

Methods of Procedure.............................................. 15

CHAPTER II: Plenary Literature Review................................... 18

History of School Nurse Practice.......................................18

Image of School Nursing...........................................23

Challenges in the School Nurse's Role.................................26

School Nurse Education...............................................31

Contemporary School Nurse Practice....................................31

Vocational Choice/Job Satisfaction Theories..................................36

CHAPTER III: Methodology...............................................40

Rationale for the Method................................................ 40

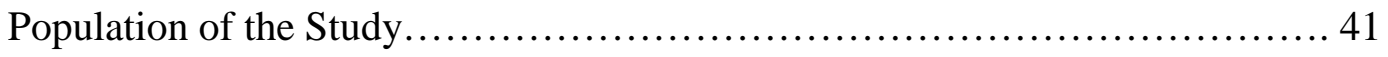

Sample..............................................................44

Procedure............................................................43 
CHAPTER IV: Qualitative Findings...................................... 46

Career Choice Rationale.............................................46

Job Satisfaction Levels.............................................53

Challenges.......................................................59

Success Definitions.................................................62

Integration of work and home life.................................67

CHAPTER V: Discussion and Implications.................................71

Interpretation of the Findings.......................................71

Potential Applications of the Findings...................................75

Biblical Integration.............................................. 75

Relation of the Findings to Other Literature..............................75

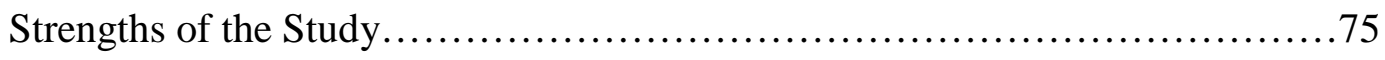

Limitations of the Study............................................77

Suggestions for Future Research.........................................78

APPENDICES............................................................. 79

APPENDIX A: Interview Questions...................................79

APPENDIX B: Demographic Data.....................................80

GRAPH: School Nurses...........................................81

TABLE: School Nurses............................................ 82

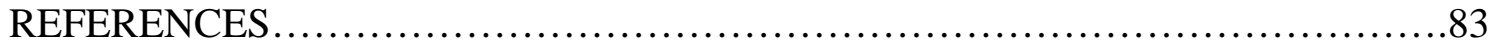




\title{
ACKNOWLEGEMENTS
}

\author{
All glory and honor belong to the LORD, JESUS CHRIST, my SAVIOR who \\ made the completion of this thesis possible. I want to also thank my family, \\ especially my son, Matthew, and my daughter, Lydia who liberally encouraged me in \\ my academic efforts. Thank you to Dr. Gruber and Dr. Firmin for their continued \\ support during this project. Thanks to all the school nurse participants who \\ generously gave of their time and shared their thoughts with me. Finally, thanks to D.
} England. 


\section{Chapter 1}

Introduction to the Investigation

Nurses generally are favorably regarded by the American public (Buerhaus, Donelan, Ulrich, Norman, \& Dittus, 2005). In a recent Gallup survey, Americans attributed the highest perception of honesty and ethics to the nursing profession when compared to approximately 20 other listed professions (CBC News, 2004). This ranking of nurses exceeded the ranking of physicians and clergy in the same survey, suggesting a substantial degree of confidence that the public places in nurses.

Images of Nursing

Although the public has high regard for the character of nurses, there is concern regarding the public’s image of nursing as a respected and intellectually challenging profession (Bridges, 1990; Gordon, 2004). In a literature review on the images of nursing, Bridges (1990) identified four prominent stereotypes of nurses portrayed in the media: the ministering angel, the battleaxe matron, the sex symbol, and the doctor's handmaiden. Vestiges of some of these images continue to be used by the media. The nurse as a ministering angel emerged in the late $19^{\text {th }}$ century (Bridges) and was influenced by women in religious orders who provided nursing care. The battleaxe matron, an image of a fearsome overweight, authoritarian, senior-nurse may have originated in early nursing at the time of Florence Nightingale. Bridges related that Nightingale usually appointed middle-class, single women as her matrons who often exercised control over the work and personal lives of younger nurses. The sex symbol image of nursing appeared in the media of the 1960's and 1970's at the rise of the women’s movement (Kalisch \& Kalisch, 1982). Throughout nursings' history, the view 
of the nurse as the doctor's handmaiden has been prominent and, according to Bridges, viewed by the public as being the most realistic image of nursing.

In their review of films in the motion picture industry that portrayed nurses, Kalisch and Kalisch (1982) reported a fluctuation in positive and negative nursing images. In their view, the image of nursing was most positive during the 1940's when the service was seen as a most noble and natural wartime work for women. In contrast, they indicated the movies of the 1960's introduced a subtle moral erosion of the nurse's good character that led to subsequent movie denigration of the nursing profession in relatively extreme ways. They noted a relationship between the rise of sadistic nursing portrayals in the movies of the 1970's and the decline of altruism as a motive for choosing nursing as a career in the same decade.

In a study involving nurses who had worked or trained in Canada during the 1920’s or 1930’s, Keddy, Gillis, Jacobs, Burton and Rogers (1986) retrospectively examined the nurse-doctor work relationship from the perspective of nurses via interviews. They concluded that some nurses did not fit the handmaiden role. Such nurses were vocal in their opinions and acted on what they believed would improve patient care, sometimes despite doctor's orders. Often, these nurses were furtive in their actions. Keddy et al. revealed the conflicts nurses experienced that were inherent in the role of the nurse as the doctor's handmaiden and reported that, for years, nurses had been performing the traditional duties and roles of doctors, particularly on night and week-end shifts.

Negative images of nurses portrayed in the media distort the public's concept of nursing and reinforces an archaic legacy of beliefs, expectations, and myths regarding 
nursing (Kalisch \& Kalisch, 1982). These images influence the number and quality of individuals who select nursing as a career. Many people still view nurses as benevolent, female hospital employees who perform humble and simple tasks of intimate care for the infirmed who are unable to care for themselves (Meier, 1999). However, this view is outdated and incorrect. There exists a seemingly universal misunderstanding of the complexity of nursing care activities at the bedside of ill and vulnerable people (Gordon, 2004). For example, blood pressure readings are not mindless tasks, Gordon learned, but are used by hospital nurses to ascertain an individual's risk of serious and sometimes life threatening dangers such as cardiac arrest or internal bleeding after surgery.

An impending health care crisis looms in the United States' future. Currently, there are an estimated 2.9 million registered nurses in the United States (National Sample Survey of Registered Nurses, 2004), but by 2020 a nursing shortage of nearly 800,000 is projected to exist (U.S. Department of Health and Human Services, 2002). Nurses comprise the largest group of healthcare providers and are the largest cohort of employees in hospitals (Meier, 1999; Wilson, 2005). They also include a substantial percentage of the workforce in other health care settings (Seago, 2006).

Registered nurses work in a variety of community settings. For example, nurses function as educators, researchers, journal authors, flight nurses, legal consultants, executives, and school nurses (Johnson \& Johnson, 2005). These career specialties in nursing all require extensive education and the utilization of critical and innovative cognitive skills. 


\section{History of Nurse Education}

Nursing education began more than 100 years ago in hospital nurse training schools (Bullough, 1976). Nursing students became a lucrative source of inexpensive labor for hospitals when administrators hired their own students as hospital staff (Woolley, 2004). Consequently, hospital employment too often became unavailable to graduate nurses. Having no other employment options, they were forced to work in homes as private duty nurses competing with untrained workers and correspondence school graduates for jobs (Bullough).

Nursing developed into a recognized practice with specific standards through the work of two national organizations of the late $19^{\text {th }}$ century that were precursors to the National League for Nursing (NLN) and the American Nurses Association (ANA) (Bullough, 1976). They emerged to combat the proliferation of substandard nursing schools and were instrumental in the creation of state nurse registration acts (state licensure laws) to create a distinction between adequate and inadequately trained nurses. As the nurse registration acts progressively were enacted over time by individual states between 1903 and 1923, the designation of the registered nurse (RN) credential became the exclusive legal right of those individuals who had completed a nursing program acceptable to state boards and passed a board approved examination.

There are three types of pre-licensing registered nurse programs (Woolley, 2004). The 3-year hospital-based diploma program, the associate degree program (2 year colleges) and the baccalaureate program (4-year colleges and universities) all meet the educational requirements established by state boards of nursing for registered nurse 
licensing. Graduates of these programs all take the minimum competencies exam known as the National Council Licensure Examination for registered nurses (NCLEX-RN).

As a result of the three education paths to becoming a registered nurse, confusion exists among allied health professionals and the public regarding the capabilities of registered nurses with differing educational backgrounds. Diploma and associate degree nursing programs lack the community health component that is essential for public health nursing and school nursing. Registered nurses with baccalaureate degrees have the greatest opportunity for upward mobility in the profession. For example, baccalaureate degrees are a minimum requirement for nursing faculty and doctoral degrees are a prerequisite for nurse researchers. Once a nurse becomes registered, renewal at the appropriate intervals, after meeting continuing education requirements, is required to legally retain the $\mathrm{RN}$ credential. This credential is separate from the attainment of university degrees. Therefore, distinction is made between pre-licensing programs for students who are not yet registered nurses and other nursing programs that grant degrees to RNs who may have completed either a diploma program or an associate degree program and who desire continuing education to obtain a university degree.

\section{History of School Nursing}

The precedent for school nursing in the United States was developed in England during the late $19^{\text {th }}$ century (Wolfe $\&$ Selekman, 2002). The British government enacted the Education Act of 1870 that made education compulsory for all children until age 13, but the poor health of some students created a need for health services within schools (Kelsey, 2002). It was the recruitment of young men for the South African War in 18991902 that made apparent the poor health status of working-class young men. Since the 
government had a vested interest in a sufficient supply of healthy recruits for military service, this was considered the impetus for the implementation of nurses in schools. Nurses' roles were to assist in improving the health status of students, some of whom eventually would serve in the army.

Conversely, school nursing in the United States was initiated to solve the problem of absenteeism in schools. Immigrant families arrived in large numbers and entered the New York City school system. Subsequently, students' health status became an issue with regard to the rapid spread of communicable diseases, including scarlet fever, measles, mumps, and diphtheria (Rogers, 1908). These diseases were associated with high mortality and morbidity, especially among young children (Vessey \& McGowan, 2006). Unsanitary and overcrowded housing, poverty, and hunger were contributing factors in the transmission of disease. These conditions had an adverse effect on education due to the high student absenteeism that threatened the success of the compulsory school program.

Exclusion of ill students failed to halt disease. School officials initially hired physicians as medical inspectors to exclude students with infectious diseases from attending school (Wolfe \& Selekman, 2002). This method proved problematic due to a number of factors, including poor communication between the school and homes of nonEnglish speaking families, lack of understanding regarding disease and prevention among the populace, lack of medical care due to poverty, and the intermingling of excluded students as they played after school with friends or relatives who were not ill (Rogers, 1908). It became apparent that this exclusionary method as a solitary means of controlling disease was ineffective. 
Public health nursing provided the nation’s first school nurse. Renowned social reformer and founder of public health nursing, Lillian Wald, suggested an approach to the student absentee problem from a public health nursing paradigm (Buhler-Wilkerson, 1993; Vessey \& McGowan, 2006). She implemented school nursing by assigning one of her public health nurses, Lina Rogers, to four New York City schools as an experiment (Broussard, 2004). She utilized public health nursing methods including home visits, health teaching, and community collaboration of resources to meet the medical and other basic needs of families. Rogers’ approach was shown successful to significantly improve the school attendance rate by $90 \%$ after just one month of service. Twelve additional nurses were hired to continue the work Rogers initiated and Rogers was promoted to a nurse supervisory position over the other nurses. This event was an initial, rudimentary, evidenced-based school nurse practice.

The focus of general health care on the national level has changed in the latter half of the $20^{\text {th }}$ century, affecting the role of school nurses. Children, who were not previously permitted enrollment in public schools due to severe health conditions, currently are included in the student population (Wolfe \& Selekman, 2002). In the first half of the century, the focus in schools by the health care profession was on acute illnesses such as communicable diseases. In the latter half of the century, scientific advances and new technologies have redirected health care's national attention to include chronic illnesses. Children with congenital health conditions, who previously would have died in infancy, now have longer life-expectancies and are attending school with life sustaining medical equipment. These children previously had been thought to be too physically impaired to attend school. As a result, the role of the school nurse has 
expanded to provide health services to medically fragile students enrolled in public schools.

Concern for the education of handicapped children became prominent in American culture during the 1960's and 1970’s (Bradley, 2005). Several education legislations were enacted to protect the interest of handicapped students such as the 1975 Education for All Handicapped Children Act (EAHCA) that evolved into the Individuals with Disabilities Education Act (IDEA), the Rehabilitation Act of 1973, Section 504 and the American Disabilities Act. These laws ensure access of handicapped students to a free and appropriate public school education. As a result, the role of school nurses has expanded to provide the special health care requirements of students with disabilities so that these students can benefit from a public school education among their peers.

Cedar Rapids Community School District vs. Garrett F. (1999) was a prominent case argued before the United States Supreme Court in 1998, based on the Individuals with Disabilities Act (IDEA). It addressed the issue of whether a school district was required to provide related services, as defined in IDEA, to a student on a ventilator who required specific nursing services during school hours. The respondent, Garrett, was paralyzed from the neck down, attended regular classes in a typical school program, and was experiencing academic success. He required a competent person to provide for his physical care. The Supreme Court ruled that the continuous nature of the services that Garrett required, and its costs, did not absolve the school district of its responsibility to provide services under IDEA. Although it is uncommon for most public school students to require the extensive and continuous nursing services that Garrett required, other students with less complex health care needs may still require the professional judgments 
and technical expertise of school nurses. These professionals can help to fill the requirements for the accommodation of these students as established by federal legislation.

\section{Definition of school nursing}

In 1999, the National Association of School Nurses (NASN) formulated the following definition of school nursing, included in an issue brief:

School Nursing is a specialized practice of professional nursing that advances the well-being, academic success, and lifelong achievement and health of students. To that end, school nurses facilitate positive student responses to normal development; promote health and safety; intervene with actual and potential health problems; provide case management services; and actively collaborate with others to build student and family capacity for adaptation, self-management, self advocacy, and learning (NASN, 2005, p.1).

Seven roles of the school nurse are described in the NASN 2002 issue brief on school health services role in health care. These school nurse roles are (1) to provide direct health care to students and staff, (2) leadership for the provision of health services, (3) screening and referral for health conditions, (4) promote a healthy school environment (5) promote health, (6) serve in a leadership role for health policies and programs, and (7) serve as a liaison between school personnel, family, community, and health care providers.

To accomplish these roles, school nurses require appropriate educational preparation. The National Association of School Nurses' recommendations of the professional school nurse qualifications include licensure as a registered nurse and a baccalaureate degree 
from an accredited university or college. An additional recommendation is school nurse certification (licensure) by the practitioner's respective state board. NASN encourages national board certification for school nurses.

\section{Terms:}

American Nurses Association (ANA) -This is the largest national nurse organization that focuses on nurse related issues.

Bachelor of Science in Nursing (BSN) - This is a 4-year academic degree and is the prerequisite degree for graduate study. BSN programs comprise in-depth nursing courses that include theory, research, pharmacology, pathophysiology, physical assessment, and nutrition. Additionally, BSN programs include the study of specific nursing areas such as community and public health, medical-surgical, maternal-child, pediatric, mental health, and nursing leadership and management (The College Board Book of Majors, 2006; The Princeton Review Guide to College Majors, 2007).

Licensed Practical Nurse (Licensed Vocational Nurse) - This is a graduate of a school of practical nursing whose qualifications have been examined by a state board of nursing and who has been legally authorized to practice in this capacity under the supervision of a physician or registered nurse (Dorland's Illustrated Medical Dictionary, 2003).

Medically fragile- This is a term that refers to individuals with complex medical needs requiring technological support, specific services or some form of on-going medical support for survival. The term is also defined as "other health handicapped—major" for the purpose of categorization in schools (Legislative Office of Education Oversight, 2002, p.10). 
National Association of School Nurses (NASN)-This is an organization of nurses whose mission is to improve the health and educational success of children and youth by providing leadership to advance the practice of school nursing. It is the leading, worldwide expert for school health services with membership of over 14,000 nurses in the U.S. and overseas (www.nasn.org).

Nurse practitioner- Nurse practitioners are one of four classifications of advanced practice nurses (APNs). Nurse practitioners are registered nurses with master's degrees. Their advanced education and training enables them to carry out some responsibilities that traditionally were performed by physicians. There are approximately 115,000 nurse practitioners employed in the U. S. in such settings as hospitals, clinics, physicians' offices, nursing homes, mental health centers, educational institutions, student health centers, nursing schools, home health agencies, hospices, prisons, industrial organizations, the U.S. military, and other health settings including private practice. Nurse practitioners appeared subsequent to World War II in response to the acute shortage of physicians. The use of nurse practitioners also was a means for former corpsmen to utilize their medical training and experience in the void left by too few medical practitioners. The first training program for nurse practitioners was at Duke University in 1965. At Duke, it was thought that nurse practitioners could perform many of the tasks done by physicians and thus allow physicians additional time to handle more complex cases. Nurse practitioners in every state may write prescriptions, but a physician's co-signature typically is required. Initial nurse practitioner certification involves passing a written exam. Recertification usually involves completing continuing education requirements. The role of the nurse practitioner involves teaching and 
counseling in health maintenance and prevention (Encyclopedia of Careers and Vocational Guidance, 2005).

Physician Assistants (PAs)-The occupation of PAs was created in the 1960's at the time when medical corpsmen (members of a military troop) received supplemental education that allowed them to assist physicians with a variety of medical tasks. They are not nurses. The number of physician assistants has grown from approximately 100 in 1970 to 63,000 . They assist physicians in providing medical care to patients. PAs may take medical histories, conduct complete (routine) physical examinations, order laboratory tests, draw blood samples, administer injections, diagnose health conditions, prescribe treatments, and assist in surgery. They work under the direction and supervision of a licensed physician. The PAs duties are dependent on the laws of the state of employment, the practices of the supervising physician, the experience, and abilities of the individual physician assistant. All states require that PAs possess certification by the National Commission on Certification of Physician Assistants (NCCPA). In order to obtain certification, PAs first must be graduates of a PA program that has been approved by the Commission on Accreditation of Allied Health Education Programs and, secondly, they must pass the Physician Assistants National Certifying Examination (PANCE). Although most PA programs are 24 months, programs can range in duration from one year to three years (Encyclopedia of Careers and Vocational Guidance, 2005). Public Health Nurse- This individual is an especially prepared registered nurse who is employed in a community agency for the purpose of safeguarding the health of persons in the community, giving care to the sick in their homes, promoting health and well-being by teaching families the strategies necessary to promote health, and assisting in programs 
for the prevention of disease. Community health nurse and visiting nurse are synonymous terms (Dorland's Illustrated Medical Dictionary, 2003).

Registered nurse (professional nurse) - This is an individual who completed one of three pre-licensing programs (diploma, associated degree or baccalaureate program) and passed the national licensing examination known as the NCLEX-RN. Registered nurses comprise the largest health care occupation with approximately 2.4 million jobs. Three out of 5 jobs are in the hospital setting (Occupational Outlook Handbook, 2006). School Nurses- These are medical personnel who focus on the overall health of students and may work in one school, full-time, or in multiple placements part of the day or week. They have a variety of responsibilities that include assisting the school physician, if there is one at the institution, and to work in collaboration with parents, teachers, and other school personnel to meet student's health care needs. They promote health and safety, work to prevent illnesses, treat accidents and minor injuries, maintain student health records, and refer students for additional medical care, if needed. Educational requirements for school nurses vary by state. Some states require school nurse certification while other states do not have this requirement. Other states require school nurses possess BSN degrees, but some states do not require a BSN degree. There are some states that require school nurses to be registered nurses while other states employ license practical nurses (Encyclopedia of Careers and Vocational Guidance, 2005).

Statement of the Issue

The projected nurse shortage for the next decade likely will have an adverse effect on schools, since school nurses are drawn from the larger national pool of registered nurses. Currently, the professional roles and technical expertise of school nurses is 
expanding to meet the health services needs of students with a wide variety of health conditions (Wolfe \& Selekman, 2002). School districts must attract nurses to the school milieu in order to meet the expanding health services needs of students, especially those students with the most severe health conditions. To accomplish this aim, it is necessary for school administrators to have an improved understanding of school nurses and a greater knowledge regarding their unique perspectives. Identifying the characteristics of school nurses and their perspectives of the school nurse specialty can be advantageous in the recruitment of new nurses and the retention of current school nurses. Presently, little is known empirically about this population of professionals. The research literature does not provide a clear picture regarding the values that comprise this group, nor does it illuminate the factors that attract RN's to assume school nurse positions. The present research aims to contribute to this salient need.

Scope of the Study and Delimitations

The present study explored perceptions that school nurses related regarding reasons current school nurses, in a large Midwestern urban public school district, chose their career specialty. Data were collected from a purposive sample of 25 school nurses from a population of 103 school nurses in the district selected for this study. Criteria for the sample were nurses who have been employed for 3-22 years and who possessed elementary public school assignments and BSN degrees. The study did not include school nurses who worked in non-public school assignments, possess advanced degrees, or did not work in an elementary school. Data were collected through personal audio-taped interviews, using a researcher-designed semi-structured interview format. 


\section{Significance of the Study}

The literature is replete with information regarding hospital nurses, but a relative paucity in the literature exists regarding what school nurses value in their positions or the reasons nurses choose school nursing as a career. Through data-base searches in the research literature (Cinahl Plus, Academic Search Premier, ERIC, Medline, Vocational and Career Collection, Health Source, Psychology and Behavioral Science Collection), no studies were located involving qualitative designs in the United States that focused on the reasons nurses chose school nursing as a professional nurse specialty or their initial and current perceptions of their roles in schools. Consequently, the current study will be an original contribution to the literature.

\section{Method of Procedure}

\section{Research Question}

What reasons do nurses give for selecting and maintaining school nursing as their career choice?

Type of study:

This is a phenomenological, qualitative research study that explored the perspectives of school nurses' vocational satisfaction. I utilized semi-structured, personal interviews. The constructs I investigated included reasons for career choice, job satisfaction and challenges, success definitions, and integration with home life. Sample

The sample consisted of 25 currently employed school nurses who work in elementary public school assignments within the Columbus City Schools District. The Columbus City Schools District comprises approximately 59,000 students. There are 
4,776 students who come from homes where the primary language is not English.

Approximately $71 \%$ of students qualify for free and reduced-price meals, approximately 500 students are believed to be homeless and 400 are in the foster care system (Harris, 2006).

\section{Data Collection}

The 20 to 30 minute interviews focused on four constructs: reasons for vocational choice, job satisfaction and challenges, success definitions, and integration with home life. All interviews were audio-taped recorded and transcribed for later analysis. All 25 participants were interviewed once. A second wave of interviews was conducted on a select group of nurses for clarification and resolution of apparent contradictions until saturation of the data was achieved. Additionally, I enlisted various participants in member checks to ascertain the degree to which participants agreed with the general findings of the study, thus enhancing internal validity.

\section{Data Analysis}

In analyzing the data, I used the process of breaking down, examining, comparing, conceptualizing, and categorizing data (Strauss \& Corbin, 1990). This method was used in order to assess potential common themes among four constructs. I included emerging codes and removed ones that did not recur frequently in the interviews. The first round of analysis resulted in a master-list of codes. I continued to review the data for findings that were repeated among participants interviewed in the study using constant-comparison analysis (Glaser \& Strauss, 1967). Codes were combined when practical and some categories were collapsed in order to keep the results manageable. The tentative results were shared with selected research participants 
(member checking) in order to enhance internal validity of the study's results. Internal validity was enhanced by generating a data-trail and having the conclusions reviewed via independent analysis. 


\section{Chapter 2: Plenary Literature Review}

Two salient topics in the school nurse literature include the role and the educational preparation of the school nurse (American Academy of Pediatrics, 2001; Bigby, 2004; Grant, 2001; Macdonough, 2001; Percy, 2006). The function of the school nurse has varied since its origin and the variations in the school nurse's role have resulted from a combination of societal changes. Prior to the 1960's, schools excluded children who were perceived as uneducable and unable to benefit from a public school education (Spring, 2001). As a result of multiple education legislations, from the Elementary and Secondary Education Act of 1965 to the No Child Left Behind of 2002, all school-aged children now have access to a public school education. Societal views have changed regarding the educability of children with disabilities. The role of the school nurse has necessarily been altered to include the provision of care for students with a broader spectrum of health issues than the ones initially encountered in schools by the first school nurse.

\section{History of School Nurse Practice}

Prior to the initiation of school nursing, the impact of nursing interventions on disease containment and students' attendance rates was unknown in the United States until 1902 when it was demonstrated in New York City by the first school nurse, Lina Rogers (Dock, 1902; Rogers, 1908). Rogers’ tasks involved assisting doctors with inspection of students, performing treatment protocols for minor illnesses, instructing in hygiene, and visiting students' homes after school for direct communication with parents regarding health promotion, prevention and referral to community resources. With the assistance of another Henry Street Settlement nurse, Rogers was able to substantially 
improve the health status and attendance rates of students in her assigned schools (Hawkins, Hayes, \& Corliss, 1994). Her public health nursing experience enabled Rogers to gain knowledge of community health issues and procure resources to support families in economic, health related, or other crisis. The effectiveness of the emerging role of the nurse in school milieus was evident. Additional nurses were hired by the school system and one year later students' absentee rates decreased from 10,567 in September of 1902 to 1,101 in September of 1903 (Rogers, 1908). Thus, health and education became inextricably linked in the public school system.

The scope of practice for the nation's early school nurses was broad and innovative during the first decades (Hawkins, Hayes, \& Corliss, 1994). The main objectives of the early school nurses included the containment of disease through assisting physicians with inspections and examinations (Zaiger, 2000), access to medical care, and health promotion in schools, homes, and the community-at-large. These objectives were appropriate in providing services for the impoverished immigrant population who, at that time, were transitioning from an agrarian culture in their countries of origin to an urban culture in the United States. As school nursing spread to other parts of the nation, prenatal clinics, well-child clinics, and oral and health education programs were developed by nurses. Child labor issues also were a concern of early school nurses as school nurses were required to distribute work permits to adolescent students deemed physically fit to work in order to supplement their families' incomes. In sum, school nurses were a visible force in the community.

Prior to the 1920's, opposition arose from private physicians regarding the referral activities of school nurses and the delivery of medical care in schools. School nurses not 
only referred students of indigent families to dispensaries for medical care, but they also referred the patients of private doctors to dispensaries who could not afford doctor's fees. Additionally, some municipal health departments in large cities with significant immigrant populations provided medical, dental, and social services in schools. Through the hegemony of the American Medical Association, physicians exercised a substantial influence on narrowing the scope of school health services and school nurse practice after the initial two decades of school nursing (Lear, Isaacs, \& Knickman, 2006). The robust emergence of school nurse interventions included health promotion, prevention, and health referrals for students and families.

Unfortunately, these interventions, comprising the rudimentary school health program, did not prevent the eventual narrowing of school nurse practice to administering first aid, emergency services, periodic student screenings, and documentation of compliance to district or state health requirements. Generally, the expansion of school health services was viewed as a threat to physicians' private practice. Hawkins, Hayes and Corliss (1994) indicated that, after World War II, school nurses diminished their involvement with health teaching in classrooms and home visits, while consultations with teachers increased. Regan (1976) also noted that the literature indicated a general lack of preparedness among most school nurses regarding the role of health educator in classrooms, although they successfully provided individualized and informal health teaching. The lack of appropriate health and education courses in schools of nursing were identified as contributing factors. Thus, according to Regan, the responsibility of health education shifted from nurses to teachers as health information became an integrated element of the educational program of the schools. 


\section{School Health Programs}

The 1940's and 1950's were times of increased population in cities due to migration from the southern United States and Europe. These populations were seeking improved economic conditions, but this created greater numbers of people living in ghetto and poverty neighborhoods. The 1960-1970's generally were decades of expansion for the role of the school nurse in an attempt to provide access to healthcare for people without health insurance. The concept of school health programs was introduced as a primary health model (Hawkins, Hayes, \& Corliss, 1994). Schools were viewed as logical sites for the provision of healthcare for students. The school nurse, in an expanded role, was seen as one who could provide health care to students through schoolbased clinics. School nurse practitioner programs were developed to ease the problem of inaccessible health care. The first school nurse practitioner program originated at the University of Colorado in 1970. Graduates of the program were trained to provide the primary care of school children as a solution to the inaccessibility of physicians for many of the population. As health care providers, school nurse practitioners are able to provide valuable services to school children who would otherwise not receive needed health care service or at best receive fragmented care (Silver, 1980).

In the second half of the $20^{\text {th }}$ century, the perception of the school nurse's duty by lay persons was incongruent with the perception of school nurses regarding their actual primary function as evidenced in letters to the editor of RN magazine in 1966. The public narrowly viewed the school nurse as a provider of first aid and care-taker of sick and injured students. School nurses, in contrast, saw their profession in broader terms. For example, the school nurse's responsibility in a New Jersey school district during the 
1960's was described as encompassing the integration of both the medical and educational aspects of the position (Gorlick, 1967). Medical and educational integration was accomplished by collaborating with the school medical team and the parent/teachers' associations to provide nursing services for pre-kindergarten children during the annual preschool roundup. Parents brought prospective kindergarteners by appointment for health assessments, such as vision and hearing screens, and health interviews during which parents were encouraged to discuss those issues pertaining to the child's health with the school nurse. The visit was viewed by the school nurse as a foundation in establishing health as an important issue to the school and it created a positive experience for the child (Gorlick).

\section{School Legislation}

School legislation enacted since 1965 has significantly influenced the practice of school nursing by providing Title I funds for school nurse salaries and expanding school health services (Kort, 1984). Title I of the 1965 Elementary and Secondary Education Act was one of the first laws in which the federal government committed funds to states in order to assist in improving the education of all students, particularly students from economically impoverished families in both urban and rural areas. The Title I funds enabled some schools to hire school nurses for the first time, thus providing nursing services to educationally disadvantaged students ("School Nurse and Teacher Too," 1969; Gregory, 2006). 


\section{Image of School Nursing}

The practice of school nursing has been noted to be poorly understood by many constituents in society (Oda, 1991), thus affecting its image. School nursing is not practiced in a health care setting like most nursing specialties, but rather in an educational one. As such, the primary mission of educational institutions is related to education, not health. Educators often have narrow views of school nursing. In their view, school nursing primarily involves the performance of minor, first aid tasks or emergency interventions, although emergencies are rare occurrences. Oda states that while the nursing profession may have an image problem, school nursing tends to have a "no image” or invisibility problem, because much of school nurse practice is invisible to educators and the general public.

The school population, unlike clients in health care settings, generally is regarded as a "well" population. Legislation allowing school-aged children access to a free and appropriate public school education has changed the predominately well population to include children with a wide-range of health conditions not traditionally seen in schools prior to the decade of the 1960 's. The preventative and health promotion instruction of school nurses to individual students goes unnoticed unless it takes place in classrooms and is delivered to groups of students (Oda, 1991).

Some student health conditions are complex and potentially life-threatening. They require appropriate monitoring and timely interventions during the school day. These interventions are not simply a matter of performing health related tasks, such as medication administration, inhalation or aerosol treatments for asthma, or blood glucose monitoring of students with diabetes. Rather, these interventions require professional, 
nursing judgment. For example, Anderson, et al. (2005), in their study involving Michigan elementary schools, advocated for the importance of nursing services to assist students in achieving optimal control of asthma in the school setting. They found that educators (including administrators), students, and parents had significant information deficits regarding the appropriate care of students with asthma.

\section{Transition to School Nursing}

Nurses who transition from other nursing specialties in order to enter school nursing often are surprised to discover the complexities of the school nurse's role according to Harvey (1998). She advocates that the nursing perspective of a novice school nurse must undergo a transformation from an acute care nursing model, based on disease and injury, to a public health model that encompasses preventative and health promotional interventions. This transformation requires the acquisition of skills that are typically descriptive of other specialists such as counseling, teaching, and social services. Excellent clinical nursing skills, such as those typically used in hospitals, are not sufficient for success in school nursing, although such skills are important (in Harvey's view). School nurses also must possess expertise in pediatric nursing, public health, and mental health. The nursing shortage exacerbates the problem of locating qualified school nurses according to Houghton (2003). Providing mentorship for novice school nurses through teaching, advising, and supporting them—ultimately benefits students and encourages successful school nurse practice and retention of nurses in the school nursing specialty (Houghton). 


\section{Marginalization of the School Nurse}

The school environment can present barriers to the effectiveness of the school nurse in contemporary times. There exists confusion among educators and the general public regarding the role of the school nurse (Constante, 2002; Foley, Lee, Wilson, Cureton, \& Canham, 2004). The pervasive misconception of the school nurse's role as the official dispenser of band-aids typically communicates a general lack of respect for the educational preparation and experience of individual school nurses and the school nursing profession. The school nurse may experience feelings of marginalization that can result in diminished job satisfaction (Smith, 2004). Isolation, lack of administrative support, environmental limitations, and time constraints can intensify feelings of marginalization for school nurses. Most professional nurse careers are in healthcare settings where, as a group, nurses have greater respect and value. In contrast, the school nurse is isolated from nurse colleagues in a milieu where the primary purpose is education and not health. Houghton (2003) indicates that at the onset of their careers, school nurses may experience isolation, discomfort, and uncertainty regarding their responsibilities. These feelings may result in job dissatisfaction and withdrawal from the school setting. Houghton advocates mentoring programs in order to build confidence and clarity for school nurses as they adapt to their new roles.

School Health Services and Parents

The levels of health services provided in public school districts across the nation vary (Francis, Hemmat, Treloar, \& Yarandi, 1996). For example, Clark, Clasen, Stolfi and Jaballas (2002) conducted a study involving the Dayton Public School District with a student population of 24,000. They assessed the knowledge and opinions of the parents 
of third grade students regarding school health services. The range of health services available included 1) health screenings, 2) report or investigation of suspected child abuse or neglect, 3) health care by a nurse for an injury or acute medical problem, 4) control of communicable disease, 5) medication administration for children with special health care needs, 6) immunization clinics, 7) consultation with parents regarding children's health problems, 8) well-child exams through HealthChek, 9) health education for teachers, parents, and children, 10) review of health records, 11) referrals for followup care, 12) arrangement of athletic or work physical exams, and 13) medical exam for an acute medical problem. Most parents were aware of only five of the thirteen health services provided by the school district. Parents identified 1) health screenings, 2) report of suspected child abuse or neglect, 3) care of injuries or acute medical problems, 4) inspection of children for communicable disease control, and 5) medication administration of children with special needs as the health services provided by the school district. Although parents believed all the services listed were important, the researchers found a significant lack of communication with parents regarding available school health services. Parents were not aware that their own children were receiving many of the health services provided by the school district.

\section{Challenges in the School Nurse Role}

Frequently employed as the solitary health professional in an educational setting, the school nurse’s experience can be a demanding and difficult one (Simmons, 2002). For example, in a study involving school nurses in Pennsylvania, Zimmerman, Wagoner and Kelly (1996) found that participants experienced role ambiguity and role strain between the expectations in their work environments and their professional roles as 
defined in the state's nurse practice act. This phenomenon was attributed to the conflicting and unclear expectations of the school nurse's role by the school board.

Budgetary constraints and the absence of plenary data regarding the effectiveness of school nurses have led some school systems to reconsider the necessity of using school nurses to provide health services (Maughan, 2003). The perception of some administrators regarding the school nurse's role is to perform specific tasks rather than routinely exercise professional judgments (Tetuan, 2004). This viewpoint may be a factor in the decisions of some administrators to use a variety of other school personnel as substitutes for the school nurse position such as secretaries, teachers' aides and other unlicensed assistive personnel (Francis, Hemmat, Treloar, \& Yarandi, 1996; Weber, 2007).

Parents and school administrators often are not knowledgeable regarding the liability of school nurses and the professional standards that they are legally required to uphold (Solum, 2003). As a result, parents and school personnel, including administrators, may request action of the school nurse that is inconsistent with the nurse practice act in that state. Knowledge of state nurse practice acts is paramount for schools to avoid jeopardizing the safety of students and incurring unnecessary liability. The school nurse is an asset for school personnel in establishing safe practice for the benefit of students (Solum).

School nurse researchers recognize a need for empirical data that connects school nurse interventions and student achievement (Selekman \& Guilday, 2003). Leaders in the nursing field believe that such research will assist in supporting the rationale for the allocation of funds to hire more school nurses. The link between student achievement 
and school nurse interventions can be shown compatible with the overall educational mission of the school. The positive effects of school nursing interventions have been long-noted. However, health maintenance, disease prevention, safety, and counseling are not easily quantifiable in a school nurse's daily activities (Oda, 1979). Yet, according to Selekman \& Guilday, many school nurses presently are evaluated on the basis of the number and frequency of the tasks they complete. The researchers recommend an outcomes' measurement of school nurse interventions regarding students that demonstrate the accountability and effectiveness of those interventions.

Student attendance is one area described in the research literature where school nurses have been shown to exert positive impacts (Wyman, 2005). For example, Allen (2003) conducted a study relating the accessibility of students to a full-time school nurse and student attendance in school. Likewise, Wyman compared the number of students released early from school by school nurses and non-nursing personnel in a Midwestern urban school district. Both studies indicated similar findings of positive correlations between higher student attendance rates and student accessibility to a full-time school nurse. Allen concluded that the allocation of funds to schools was impacted by the number of students enrolled and attendance rates. In this way, school nurses may be more cost effective for schools than is currently recognized by administrators.

Guttu, Engelke, and Swanson (2004) state that a need exists for school nurse research focusing on the academic outcomes of school health services. In times of high nurse-to-student ratios in schools and declining funding for school nurses, data is needed to show the relationship between nurse/student ratios and the impact of health services on student health. Their study on nurse-to-student ratios demonstrated a correlation between 
lower nurse-to-student ratios and the identification of children with chronic illnesses and involvement of the school nurse with their care. They concluded that the availability of the school nurse promotes student well-being and a safe school environment. This view concurs with the National Association of School Nurses' (NASN) recommendation of a nurse-to-student ratio of 1:750 for students in the general population (NASN, 2006).

The role of the school nurse in contemporary society is complex and encompasses the multiple needs with which students arrive to school that potentially have an impact on their learning. Communicable disease, such as those affecting attendance in the early 1900's no longer is a primary school issue in contemporary society. Successful mass immunization programs have improved the health of the community-at-large. Students are absent for more reasons than disease contagion and have a multitude of health needs involving medical, social, and psychological factors (Maughan, 2003). The enactments of the Education for All Handicapped Children of 1975 and the Individuals with Disabilities Act have resulted in access to a free an appropriate public school education for increased numbers of students with a wide spectrum of health conditions.

In recent years, the physical safety of students has become a critical issue in schools due to increased violence; likewise, the health safety of students with lifethreatening illnesses is also a vital school issue. Rehm (2002), for example, conducted an interpretive study describing how families, educators, and care providers ensured the safety and health of medically fragile/technologically dependent children in the school setting. This study elucidated parents' expectation of school personnel to provide appropriate health related care for their children with complex health conditions in a way that ensured both their safety (survival) and academic achievement at school. Rehm 
affirmed that multiple responsibilities of the district's school nurses to hundreds of school children precluded them from being the sole providers of care to medically fragile students who represent a small percentage of the total student population. Even so, nurses had the responsibility and discretion to supervise, train, and certify teachers and educational aides in providing necessary health services to these students. During the study, the school district was faced with a contemporary issue of rising concern when it was provided written, do-not-resuscitate orders (DNR) for a student. This situation required the school district to formulate a policy regarding DNR orders for school personnel to implement. DNR orders represent one of several current issues in schools impacting the role of school nurses not seen in previous decades.

Individual education programs (IEP's) are essential to ensure that students with special educational needs identified by IDEA guidelines have their needs met in the school setting (Bigby, 2004). Bigby related that when students have been evaluated and identified as possessing a diagnosis requiring related health services, the school nurse becomes a vital member of the school team. Just as IEP's are essential in order to insure that the special educational needs of students are properly addressed in the school setting, school nurses also develop individualized health plans (IHP's) for students with specific health care needs. The school nurse is a needed member of the intervention assessment team to address the health needs of students impacting their education experience. 


\section{School Nurse Education}

National standards that specify entry-level education and experience for school nurses are non-existent (Constante, 2002). Consequently, school nurses throughout the nation have differing nurse licenses, varying levels of education, credentials and certificates. The most common professional preparation of school nurses is a current registered nurse license, and usually a baccalaureate degree in nursing (Bradley, 1997). It is Bradley's assertion that nurses who provide school health services may be license practical nurses (LPN's), registered nurses (RN's) or nurse practitioners (NP's). There are opposing views on the educational requirements of entry-level school nurses. One perspective is that school nurses only need to possess registered nurse licenses to work effectively in schools. Others believe that entry-level school nurses should be master'slevel prepared nurses (Keller, 2004). However, the National Association of School Nurses' (NASN, 2002) recommendation is the most commonly accepted one, although these suggestions are not national mandates: a registered nurse license, baccalaureate degree from an accredited institution and (where required) state certification or licensure, for school nursing.

\section{Contemporary School Nurse Practice}

School nurses practice in diversified settings. These settings may include the health office, classrooms, auditorium, or students' homes and they are significantly different from the compact, physically comfortable, and assessable environment of many hospital work stations (Macdonough, 2001). For this reason, flexibility in the use of time to complete tasks and the space within which the work is done becomes a necessary component of the job. School nurses often work in less than ideal circumstances, with 
limited space and time constraints, while performing excessive amounts of urgent tasks (Percy, 2006).

At the onset of the school year, school nurse practice involves significant amounts of time, including the monitoring of students' compliance to state immunization mandates. The school nurse accomplishes this objective through the review of students' immunization records (Bigby (2004). Additionally, Johnson (2004) discovered, in her observation of school nurses, that any number of school nurse activities, such as health screenings, accessing for acute illnesses, monitoring chronic conditions, administering first aid, and reporting suspected child abuse or neglect cases, can be part of a typical school nurse workday. Some school nurse activities are simultaneously conducted when multiple clients, comprised of students, staff, or parents-access the health office at the same time through direct contact or by telephone.

Hootman (1994) related that many students possess complex health conditions that require skilled nursing care in the school setting. School nursing literature discusses some of the gravest student health conditions school nurses encounter. They include diabetes, severe food allergies, asthma, multiple physical disabilities or medically fragile conditions, and mental health issues (Bierschbach, Cooper, \& Liedl, 2004; Gelfman \& Schwab, 2000; Hootman, Houck, \& King, 2003; Munoz-Furlong, 2006). Effective care of these students require the professional judgment as well as expert clinical skills of the school nurse. For this reason, The National Association of School Nurses (NASN) advocates that every student deserves the services of a qualified school nurse (NASN, 2002). 
Bierschbach, Cooper, and Liedl (2004) advocate that school nurses must remain current with advances in diabetes care. Technological advances have made it possible for some students with diabetes mellitus to have continuous subcutaneous insulin infusion devices known as insulin pumps. The insulin pump replaces the need for insulin injections as it provides a basal rate of insulin, programmed at home by parents or guardians, at the direction of the health care provider. Prior to food intake, the student must receive a "bolus" of insulin for the carbohydrates contained in the meal. As one concrete example of remaining current in technological medical advances, Bierschblach et al. note that school nurses need to learn to use insulin pumps in the management of diabetes for students who use this device. Monitoring blood glucose levels, diet, and activity is an important aspect of caring for students with diabetes regardless of their specific treatment regime.

Munoz-Furlong (2006), founder of the Food Allergy Network, states that approximately 600,000 children exist in the U.S. with peanut allergies. The Food Allergy Network created a comprehensive program known as The School Food Allergy Program for school personnel to assist students with severe food allergies. This program enables school nurses to provide information to school staff regarding the necessarily swift emergency action required to assist students who may ingest, or by some other means, come in contact with an allergen to which they have a severe allergic reaction. According to "Guidelines for Urgent Care in Schools" (1990), true medical emergencies are rare in schools. Even so, the current situation, in which many school nurses have multiple school assignments, predisposes the possibility of an emergency occurring in a school when the school nurse is not present. The Food Allergy Network organization 
established recommendations for school personnel to help students with severe allergies by assisting staff in identifying an allergic episode and administering prescribed medication that has been provided for the student. This includes the administration of epinephrine (epipen) and summoning emergency medical personnel to transport the student to an emergency room for additional treatment and monitoring. The Food Allergy Network organization believes school nurses are vital in implementing this program.

The prevalence of asthma is increasing in the United States (Major, Clarke, Cardenas, Taylor-Fishwick, Kelly, \& Butterfoss, 2006). In a study they conducted in Virginia involving school nurses, Major et al. discovered barriers that school nurses experienced in providing effective care for students with asthma. These barriers were described as deficits in various areas identified by school nurses. One barrier was the lack of adequate asthma education for affected students, their parents, physicians, teachers, administrators and even school nurses. Other barriers included the lack of asthma medication and equipment in schools and at home, lack of communication between parents, physicians, and schools. A final hindrance was a lack of professional respect for school nurses by students, parents, physicians, teachers, and administrators. School nurses perceived that their qualification as apt healthcare professionals was in doubt vis-à-vis the view of these stakeholders.

School personnel are challenged to determine if the medical procedures required by medically fragile students are the responsibility of school health services or whether they are considered excluded services (Bigby, 2004). These students may require time intensive, continual monitoring of various body functions of the respiratory, circulatory 
and waste elimination systems. Examples of difficulties include students in wheelchairs with oxygen tanks, having urinary catheters, or requiring intermittent catherizations at specific times during the school day. Esperat, Moss, Roberts, Kerr, and Green (1999) acknowledged the complexity and demands placed on school nurses in the care of children with complex health care needs. They reported that the amount of time and the type of care that school nurses need to know in order to provide services to students with special needs, as well as students with traditional childhood problems, are prompting ethical and legal questions and concerns.

School children are diagnosed with mental and emotional disorders in increasing numbers (Hootman, Houck, \& King, 2003). Some students with mental health issues are frequent visitors to the health office with somatic complains. Students with unexplained symptoms of physical illness that negatively impact school attendance have an increased likelihood of experiencing academic problems. DeSocio and Hootman (2004) describe a case study that highlights the vital work of the school nurse in identifying a student's needs and accessing necessary mental health and other community services for the student and her family. School nurses possess strategic positions for building relationships with students so that when intervention is necessary, a supportive relational foundation is in place (Hootman, Houck, \& King, 2003).

Emergency care of students does not comprise the majority of the school nurse's responsibilities, but school nurses must be able to intervene in school emergencies or crises (Bigby, 2004). School nurses throughout the nation possess varying qualifications, since state requirements regarding school nurses also vary. Bigby suggests that many school nurses, in fact, possess advanced degrees and health education training, in addition 
to a school nurse license. It is Bigby's assertion that most school nurses also possess valid CPR and first aid cards.

Grant (2001), in describing the functions of the nurse in the provision of school health services, states that school nurses not only should address the health needs of students, but also provide students' families, staff and the community with assistance as needed. School nurses interpret the health needs of students to parents and teachers. Additionally, school nurses adhere to standards of state and local health departments in the control of communicable diseases and reporting procedures. Grant indicates that by collaborating with various community workers, including physicians and family welfare agencies, school nurses are active contributors to the community health system.

A substantial part of school nurses’ work is unscheduled, because students access the health office according to their needs. Junious, Johnson, Peters, Markham, Kelder, and Yacoubian (2004) explored job satisfaction among school nurses and found that the inability to cope with the multiple interruptions during the workday constituted an area of dissatisfaction in the job. New school nurses often are overwhelmed with the plethora of roles expected of them, according to Wolfe (2006). However, the responsibilities of school nurses are expected to expand as educational reform and medical technology continues to advance (Wolfe). The autonomous nature of the profession requires a broadbased knowledge of numerous disciplines.

\section{Vocation Choice/Job Satisfaction Theories}

School nursing requires autonomous application of nursing theory and skill in communicating with a variety of school personnel, students, and parents — many of whom have inaccurate perceptions of school nursing. The topic of vocational choice is 
significant to the present scholarly discussion, because it provides insight into the potential reasons that impel individuals to select particular careers and their degree of adaptation and satisfaction in those careers. Commonalities exist in the literature regarding the reasons individuals choose nursing as a profession (Beck, 2000; Prater \& McEwen, 2006; While \& Blackman, 1998). Most of the reasons are altruistic in nature. Vocational psychology often focuses on individual choices of particular occupations and their satisfaction and productivity in it (Furnham, 2001). Prominent in the literature regarding vocational choice is the seminal work of John Holland (1959). He posited that vocational choice is a complex interaction of personality and environment. This is identified as the person-environment fit theory. In summary, Holland believed that individuals seek a congruency between their personal needs and the characteristics of the work environment that fulfill these needs. Job satisfaction is the result of a successful match between personal needs as a factor in personality and the work environment. He created a model of six categories of psychological features shared among occupational groups. These categories include realistic, investigative, artistic, social, enterprising and conventional—known by the acronym, RIASEC. Holland's model does not describe specific and discrete occupational entities (Holland, 1959; Furnham, 2001) such as nursing, but categorizes occupations in aggregate form. Holland's theory is considered distinctive in that it explicitly acknowledges the role of personality in vocational choice.

Conversely, Takase, Maude and Manias (2005) believe that many nursing researchers have been influenced by Kanter's (2000) theory of organizational structure. Kanter's theory states that organizational factors involving a perceived power structure 
and the perception of employees' accessibility to resources and autonomous practice have an impact on employee work behaviors. Regarding power in management, for instance, Kanter's position is that the position, and not the person, determines power. Employees who perceive their managers as influential in both the hierarchal structure and also laterally among their peers possess an enhanced status by association with the manager. This typically results in high morale and less resistance to their boss. While this theory does not address school nurses per se, it applies as a theory regarding job satisfaction and relates to the issue of employee morale, including school nurse morale. Takase, Maude and Manias, however, suggest that Kanter's theory may not adequately address job dissatisfaction and job turnover among nurses and that an alternative approach to these issues is appropriate. It is their view that nursing studies tend to examine nurses' needs and the effects of the work environment separately. Takase et al. define environmental characteristics as the occupational and organizational conditions that affect nursing practice and nurses. Their recommendation is that nurse researchers consider personenvironment fit theories as an alternative approach to the study of nurse job satisfaction and turnover. As such, they should acknowledge the attributes that nurses bring to the work environment and the environmental characteristics that correspond to those of the nurse.

In this theoretical context, a paucity of school nurse literature exists regarding reasons given by currently employed school nurses for selecting the school nurse specialty. In a study conducted in Great Britain, Thurtle (1996) concluded that, while school nurses chose the school nurse specialty for its compatibility with other aspects of their lives such as family commitments, they remained in their careers because it was 
personally satisfying. The study's participants were viewed as possessing enthusiastic, committed, child-centered approaches to their work. Thurtle's research has yet to be replicated in the United States - and this construct is particularly germane for advancing the school nurse profession. 


\section{Chapter 3: Methodology}

Introduction to the Method

In the present study, I used a qualitative, phenomenological research design. The goal was to explore reasons nurses present for choosing school nursing as a career and their perceptions regarding job satisfaction. To achieve this, I administered a questionnaire of 10 questions and conducted audio-taped, (in person) interviews with 25 currently employed school nurses in Columbus City Schools. The participants in the sample met specific and predetermined criteria. Prior to each interview, I provided a letter of introduction provided by the Columbus City Schools research proposal review committee that was read by the prospective participants and I obtained written, informed consent via them signing a presented form. A written demographic data form also was completed by the participants prior to the interview. The duration of each interview was approximately 20-30 minutes.

\section{Rational for the Method}

Through qualitative interviews, in-depth information can be obtained regarding a participant's thoughts, beliefs, motivations, knowledge, reasoning and feelings about a topic (Johnson \& Christensen 2004). Although research literature exists on health topics in which school nurses are influential, a dearth of research remains regarding the reasons nurses select school nursing as a career, school nurses’ perspectives regarding their career, and their perspectives on the nature of the work and job satisfaction. 


\section{Population of the Study}

The population for the study comprised 103 school nurses employed by the Columbus City Schools District. The Columbus City Schools District comprises approximately 59,000 students in 130 school buildings (Harris, 2006). Most school nurses have multiple building assignments. External validity for the study is limited to urban school districts of comparable sizes that employ nurses with similar education and experiences vis-à-vis the participants in the present study.

\section{Demographic data of the sample}

The present phenomenological study analyzed data collected from semi-structured interviews of 25 school nurses employed in a large urban public school district in Midwestern United States. There were 22 Caucasian and 3 African-American participants in the purposive sample. All of the participants were female. Their ages ranged from 32-64 years with a median age of 42 years. Participants ranged between 322 years of continuous school district employment with a median of 7 years. Additionally, they possessed a range of 1-32 years of previous nursing employment outside of school nursing with a median of 12.5 years. All of the participants possess BSN degrees. There were 19 school nurses who initially graduated from 4-year university nursing programs prior to obtaining registered nurse licensure. However, six nurses graduated from other pre-licensing registered nurse programs; three nurses graduated from associate degree programs and three nurses graduated from diploma programs. Four school nurses also possess non-nursing degrees. Of these nurses, three possess BS in Biology degrees and one nurse has a BA in Education. The participants reported memberships in professional organizations as follows: 21 nurses were members 
of the Central Ohio Association of School Nurses (COASN), 21 nurses were members of Columbus Education Association (CEA), 17 nurses were members of Ohio Association of School Nurses (OASN), and 17 nurses were members of the National Association of School Nurses (NASN). Three nurses also were members of the nursing honor society, Sigma Theta Tau. Other professional organization memberships represented by at least one nurse include the National Education Association, the American Association of Legal Nurse Consultants, and the Camp Nurse Association.

\section{Criteria}

The participants in this research study were school nurses who possess BSN degrees, possess at least one elementary school assignment, and have been employed in the school district for 3-22 years. The study did not include school nurses who worked in nonpublic school assignments, possess advanced degrees, or did not work in an elementary school. Two nurses declined participation in the study and two nurses were discovered to be outside of the research criteria, because they possessed advanced degrees. As a result, these nurses were not included in the study's sample.

\section{Rationale}

School nurses employed by the Columbus City Schools District are individuals to whom I obtained research access. Generally, there is no a priori indication that they differ substantially from other nurses employed in the Midwest region of the country. I conducted two interview waves with these individuals. All 25 nurses were interviewed once. A select group of nurses were interviewed in the second interview wave. Rich data was obtained with the two interviews so that saturation of the data was believed to have 
been accomplished. This helped insure the adequacy of the sample of individuals chosen for interviews.

Methods of Sampling

The sample from the population was obtained prior to the interviews and based on the above criteria. It was necessary to adjust the criterion of employment range from 5-15 years to 3-22 years in order to obtain the sample size believed necessary for the study. Also, the school enrollment range of 300-500 students was eliminated from the criteria as the enrollment figures in some schools did not meet the originally intended criterion.

\section{Procedure}

\section{Instruments}

The instruments for data collection included a demographic data sheet and semistructured audio-taped interviews. For the purpose of internal validity, the questionnaire for the interviews was reviewed by four school nurses who were not participants in the study, but who represented four Ohio school districts. Two school nurses were from private or parochial schools in Franklin County, one nurse was from a county in northeastern Ohio, and one nurse was from the Columbus City Schools District who was not a participant in the study. All of the nurses who reviewed the questionnaire supported the existing instrument with no recommendation for changes.

\section{Data Collection Methods}

I conducted in-person, semi-structured interviews with 25 school nurses by appointment and at various locations around the city outside of the school day. The purpose of the study was described, opportunities to ask questions were offered, and the rights of the participants were explained in a written consent that each participant read 
prior to signing. The interviews lasted approximately 20-30 minutes and were audiotaped recorded and transcribed for later analysis. The interview questions were organized around the following four constructs: factors that influenced career selection, job satisfaction and challenges, success definitions and integration with home life. By using constant comparison analysis of the transcribed data (Glaser \& Strauss, 1967), emergent themes were identified and organized into broad categories that were later collapsed and combined when possible. Transcribed interviews were selected for review in a second interview wave (Firmin, 2006) for the purpose of clarification of questionnaire responses. Six nurses participated in the second interview wave. To preserve the anonymity of the participants, while reporting the data in a readable and personable format, actual names of participants were replaced with pseudonyms.

\section{Relevant Ethical Considerations}

There were no known risks or potential harm to the participants. Participation in the study was voluntary and participants were given the option of withdrawing from the study without penalty if they wished to do so. Confidentiality was maintained as the identity of individual participants will not be disclosed by the interviewer. All interviews were conducted by appointment in a setting that was comfortable and private for the participants (Stainbeck \& Stainbeck, 1988).

\section{Methods of Data Analysis}

Data analysis involved a qualitative coding system (Glaser \& Strauss, 1967). The first round of codes consisted of comparing the recurring constructs in the data to discover emerging themes. The study's reported results focused on themes that shared consensus among the participants as a whole. Constant comparison of the transcripts 
allowed for the establishment of initial codes. Sometimes these codes were collapsed into similar categories where similar words and phrases shared natural overlap. Some codes that initially appeared relevant eventually were discarded due to lack of consensus among the participants. Open coding, (Strauss \& Corbin, 1990), was used in order to enhance the inductive nature of the research design. Themes were derived from the coded transcripts via consensus among participants. That is, the results reported here represent the phenomenological perspectives of the participants, rather than preestablished categories of inquiry. As much as humanly possible, I attempted to bracket my own biases and perspectives toward the results presented by the research participants. As such, these are their reported results, apart from my own views or perceptions.

\section{Safeguards to Internal and External Validity}

Internal validity was enhanced by the participants’ review of the emerging themes. Member checking occurred as I shared the general themes with six participants in the study. Although each individual concurred with the results of the present study, two of them expressed that the results contained data that they would not have predicted, but found reasonable and interesting. A limitation of the study is that it may not be generalizable to nurses in other school districts as this sampling was not random, but a purposive sample. Consistent with qualitative research paradigms (Johnson \& Christensen, 2004), the intent of the study was not to generalize the findings to all school nursing populations, per se, but rather to explore the perspectives of school nurses in a specific Midwest context. 


\section{Chapter 4: Findings}

The study's participants possess histories of professional work experiences in nursing specialties other than school nursing. Given the wide range of potential nursing opportunities currently available to registered nurses with baccalaureate degrees, participants' responses regarding their selection of school nursing as a career, their past and present job satisfaction levels in school nursing, challenges, success definitions, and the integration of work with home life all bring clarity to the participants' perspectives on this specialty of nursing. The insights of these school nurses assist in illuminating the personal and professional values of this cohort of school professionals.

\section{Career Choice Rationale}

Thematic analysis of the data revealed three prominent factors that nurses identified as the greatest influences on their decisions to enter school nursing. These factors included a preference for pediatric nursing in a community setting, the school nurse work schedule, and the influence of nurses who were currently in the practice of school nursing. These factors were consistently mentioned and represented the views of the majority of the sample.

\section{Preference for pediatric nursing}

The first factor influencing participants' selection of school nursing was that it involves the care of children. Pediatric nursing is child-oriented. As an aspect of pediatric nursing, school nursing primarily is focused on addressing the health needs of pediatric clients within the school milieu. The study’s participants possessed a significant interest in pediatric nursing as evident, not only in their choice of school 
nursing, but also in their previous work milieus. The previous pediatric nursing experiences of participants varied, but they shared in common a love for children. Christine illustrated: "A lot of my experience in public health has been with children and because of that, I like working in pediatrics and [I had] worked at the hospital and so it [school nursing] seemed like a good choice....” As noted, participants varied in their years of nursing experience prior to entering school nursing. Some nurses entered school nursing relatively early in their nursing careers while other nurses selected school nursing after serving many years in other pediatric nursing areas. Elizabeth explained:

I had been a pediatric nurse my entire career in some way, shape or form, so being a pediatric nurse, I think eventually you look at all of the different aspects of that and school nursing is one aspect of that, so that was an influence.

Registered nurses generally obtain their initial experiences in hospitals. However, participants in the present study preferred working with children in a community-based milieu. Hospital nursing generally involves care of seriously ill children some of whom also may be terminally ill. The treatment regime of hospitalized clients can be physically and emotionally painful for children. The suffering that the children can endure in hospitals can adversely affect some nurses. Stella explained, from her perspective: I wanted to work with kids, but emotionally, I couldn’t work with kids in the hospital, because they were too sick. It was too sad for me. So I wanted to work with kids to help educate them...so they could learn to live so they would eventually not end up in the hospitals. So I wanted to work with healthy kids and teach them preventative stuff. 
Just as the primary goal of schools is to educate students, likewise, participants identified the provision of health education for students as an appropriate function of school nurses. These instructional opportunities were identified as potentially enhancing the long-term quality of life for students. Participants found that working in the school setting with children who are in relatively good health was a more positive milieu for teaching preventative health behaviors than it would be in a hospital environment. Ashley elaborated:

I really like being around kids and it's nice to be around them in a well-setting and not always [in] a hospital setting....I had worked with really, really ill children for 10 years and then with really, really ill adults and I like being in a school setting.

In sum, pediatric nursing in a community setting such as a school was an attractive alternative for participants who had experienced other work settings where chronic or severe-symptomatic clients tended to be the norm.

Work schedule

The second factor influencing nurses’ decisions to enter school nursing was the school nurse work schedule. Having worked in pediatric, clinical areas prior to obtaining school nurse positions, nurses in the study sample were confronted with the relative incompatibility of their previous work schedules to their family responsibilities. This situation influenced participants eventually to seek other nursing employment options. In her explanation for entering school nursing, Elizabeth elaborated further:

I also feel that for me, I had a child that was getting a little older and I wanted to remain involved in his life, getting more involved in [his] activities and I thought 
this would be a way that we could spend more time together before he goes off to college. He was entering into middle school [and] high school age, so I wanted to do that, getting away from that shift change and weekends and that type of nursing....

Likewise, the work schedule was a consideration in Ashley's choice of school nursing. She additionally commented: "I would say my family life and probably stress at my previous [nursing] jobs and wanting a better schedule, not only Monday through Friday type [of] schedule, but also having additional time off to spend with my family... with my kids.” As a solution to the challenge of coordinating family responsibilities with career obligations, school nursing was recognized to have greater compatibility with family schedules than most other nursing positions. Work schedules that are antithetical to nurses’ family schedules were significantly less desirable options for individuals in the present study. Lois also weighed the importance of her work schedule with her children's needs and offered this response:

The fact that I have three children and when I decided to go get my certificate in school nursing, I was pregnant with my third child...I knew that childcare in the summertime and school breaks would be difficult, so that was another big influence that helped me determine to be a school nurse.

To summarize, the work schedule and family schedules were incongruent for participants in previous work milieus. Nurses were seeking a work option that provided congruency to family schedules. 


\section{School nurses influences}

A third factor that influenced nurses to investigate the school nurse option was the interaction participants experienced with nurses in school nurse practice. In particular, practicing school nurses had positive influences on the study's participants. Most of them had the prior experience of observing a school nurse. This observation was part of the community health clinical rotation in a BSN program. A few nurses in the sample entered a BSN program as registered nurses while the majority of participants matriculated through a BSN program that led to registered nurse licensure. It was the BSN program that offered the opportunity to meet school nurses. Other nursing programs do not offer community health nursing, thereby eliminating the possibility of exposure of nursing students to school nursing in this clinical format. Time spent with school nurses not only allowed students to observe the satisfaction school nurses experienced in their work, but also enabled students vicariously to share in the enjoyment of the school nurses' work. Charlotte described:

As I went back and got my bachelor's degree, I spent some time with a school nurse and I really enjoyed it a great deal. Initially when I was in high school, I wanted to be a teacher and I thought that would be a wonderful way to blend the two positions...that I would be in a school working with kids, but yet also doing nursing itself, so it seemed like a great way to blend the two.

School nurse mentors can assist in increasing the number of nurses interested in school nursing simply by allowing nursing students to spend time with them observing in a school. This opportunity allows students to gain information about the specialty that they otherwise might not consider as a career path. Candace recalled: "When I was a student 
at [the university] actually to finish my bachelor's...I decided to go with a school nurse and when I did that, I learned so much about school nursing.” Time spent with a school nurse served to expand participants' views of the field of professional nursing in the community, particularly as it involved school nursing. Mira elaborated:

I really love community nursing. As a nursing student, when I did my rotation in community [health] we had school nursing....and I just really loved working with the community. I felt sometimes their [students'] needs were not met and we could bring resources...eyeglasses or anything they may need. So I felt that in the hospital, you know, the resources were basically there, but sometimes in a school things may go unnoticed and that's where our school nurses kind of come in to help, even with a lot of non-nursing things. So, that was one of the big things that drew me to community and school nursing...just that ability to meet needs.

Although some participants were introduced to school nursing through a 4-year university nursing program, other participants did not have this experience. Rather, they were informally influenced by school nurses through personal contacts. Connie illustrated this occurrence:

Well, one thing was one of my friends was a school nurse and she, you know, told me all about it and wanted me to visit her school, which I did...I visited several schools before I made a decision....I liked the [school] atmosphere. It was a practical thing, I was working in [another nursing specialty] for 13 years and unfortunately...they disbanded a lot of the jobs...so I was looking for a different type of job and it all sort of happened at the same time.... 
Personal relationships with school nurses who experienced job satisfaction in their careers also were significant influences on nurses in the study. The job satisfaction friends and other nursing professionals experienced had profound influences on participants. This phenomenon communicated to the nurses in the study the potential cogent value that this future career path could hold for them. Rhonda exemplified this influence in her response:

Well, I had some friends who were doing school nursing and they liked it. My husband was overseas probably $90 \%$ of the year. I had three kids that were reaching elementary age and I needed something that fit their hours. So because they [school nurse friends] liked it and the hours, I actually took two years off and got my certificate for school nursing, but I knew I was going to have to go back to work.

In sum, participants offered a combination of factors that influenced their career decisions. School nursing was an attractive option, because it met the desire of participants to work with children and provided a work schedule that was compatible with the family needs of participants. Their exposure to school nursing when they were students in a BSN program allowed them the opportunity to observe and interact with school nurses in positive ways. The participants who did not have this experience in their nursing programs had friendships with school nurses who expressed significant satisfaction in their jobs. 


\section{Job Satisfaction Levels}

Initial perceptions vs. current perceptions

Data revealed that job satisfaction levels for participants were unstable during the initial years of school nurse practice. Particularly, job satisfaction levels fluctuated from low levels to relatively high job satisfaction levels within the first several years of school nursing. Participants indicated that their level of job satisfaction was relative to their success in transitioning to the role of school nurse. Their initial perceptions of the school nurse role were inconsistent, in many cases, with reality. The consensus of the nurses was that school nursing has a much wider scope of practice than they previously realized. They recognized that prior to becoming school nurses, their views of the profession were significantly narrow. Mary concisely stated: “As a younger graduate...I thought school nurses were just people who sat around and did ice and band-aids...just like the public believed.” The differences in the perceptions of participants regarding school nursing, before and after they were employed in school nurse positions, contributed to substantial stress in their jobs. This experience consequently had an adverse effect on job satisfaction among participants, especially during the first year of school nursing. Mary illustrated this when she described her experiences as follows:

My first year I was in [a middle school]....and [my background] as a white suburban child who grew up in [particular suburb], and I was in the pit of the ghetto where...I really had a hard time adjusting to that [situation], because I had kids coming into my office telling me these sad stories about their moms that were using 'crack' and...different things. And I didn’t think children should have 
to deal with such horrible issues...and some of them would come [to school] hungry and I went home every night crying for six months.

As also was reported by other participants, Mary considered leaving school nursing during her first year of employment. She elaborated:

I thought well, you know, there is such an overwhelming amount of need and I feel so inadequate to meet it, and then the things that I saw, the way the children were treated and stuff, I thought I just don't know if I can deal with this, you know. But then I thought, I can be the "kind" one or the "bright spot" in their day...even though they're coming to me when they're sick....I just thought I had more of a contribution to make that outweighed the negative effect it had on me... and that was enough to make me feel good about staying [in the job]. Although the premier year was difficult for all participants, the majority reported that they had never considered resigning. They recognized the first year as a transitional year to learn the culture of the school and the processes involved in meeting the expectations of the school nurse's role. Within the first year of school nursing, previous misconceptions of the role held by participants were dispelled as they learned what the role actually entailed. Sylvia recalled her initial perception of school nursing:

I kind of envisioned it as being 'light’ nursing... the very basics of first aid. That opinion has changed drastically, because I work in the inner city and... it is much, much more than first aid. In fact, that pretty much is a small part of it. It is taking care of children who are neglected, abused, have psychological disorders, major medical disorders, dealing with families that are dysfunctional, being a social 
worker and referring [families and children] to different agencies so that [they] can get help. It can be overwhelming.

The difference in the pre-employment perceptions of school nursing and the actual demands of the job created work-related stress in participants. The accompanying stress created frustration for participants when they discovered that they had to accomplish certain tasks at specified times during the school year. Some of these tasks, such as health screenings, are mandated by state law. The accomplishment of these tasks required skillful and efficient use of time, setting priorities, and flexibility in the job. Realizing that her initial views of the job were inaccurate, Mira stated:

I have three schools, so especially my first year I just didn’t know what to expect and like I said, I didn't know we would do screenings. I didn't know that I would be responsible for doing all of the paperwork and things like that, so it was overwhelming...there were times when it got real frustrating. The work of school nurses often involves accomplishing several tasks simultaneously due to the unscheduled nature of health office activities. For example, a school nurse may be documenting health screening results when one or more students enter the health office with urgent needs while, simultaneously, an irate parent telephones the health office for clarification regarding an incident that occurred the previous day. Candace admitted to experiencing moments of extreme stress in the job during her first year. She related:

There is so much multitasking. You're answering to so many people, not just students. You're answering to the parents, you're answering to the staff, you're answering to a conglomerate of people and you just wouldn't expect that. [There 
are] a lot of expectations, a lot of deadlines and a lot that needs to be done and a lot of health problems....I clearly remember one time just putting my head on the desk and thinking, I don’t think I can do this, because it was just all day long...there is always something else that hits you and it almost put me over the edge on a couple of days.

The challenges of transitioning to school nursing are well known to veteran nurses. The school milieu, with its mission of education, is a substantial contrast from traditional health care settings. Novice school nurses gradually learn to adjust to being the only health care professional in the workplace, but successful adjustment requires perseverance through the first year experience. Candace likewise summarized:

The first year of being a school nurse was absolutely the hardest. And when I was with the preceptor that I had, she told me...if you can get through the first year, you'll be fine, but that the first year is really tough.

Participants developed confidence in their abilities to function well in the school nurse's role as they accumulated experiences in a variety of situations that typically occur in the school setting. School nursing gradually became increasingly satisfying as they found success in their efforts to assist students and their families.

\section{Positive nurse-student interaction is valued}

Despite the initial difficulties experienced by participants as they transitioned into the school nurse role, nurses identified many positive aspects in the practice of school nursing, particularly pertaining to student connections. Sophia illustrated this when she noted: “It's always great to see [students'] faces light up when they get something, when they're happy, when they're healthy, when you've helped them, even if it is something as 
simple as ice or a band-aid...” Participants indicated possessing a substantial amount of compassion for students. The emotional health of students was said to be as important to participants as the students’ physical health. Perceived evidences of a general state of happiness among students are particularly affirming to participants. The interpersonal contacts with students are salient aspects of the school nurse role. Elizabeth illustrated: “It’s the smiling faces and the "hellos” everyday and knowing that you're doing some teaching with them that hopefully will make an influence...later on in life.” In short, students' well-being contributes to high job satisfaction for school nurses. Participants identified the importance of having a lasting positive health impact on students not only during their years in school, but also extending into the students' adult lives. They expressed the desire to assist students in making healthy life choices that would develop into healthful habits with positive consequences. They value meaningful contact with students and consider time spent while counseling troubled students to be of greater value than merely supplying students with ice packs or band-aids. Pat, for example, commented: “It really makes me feel good to know that I'm helping them [students and families] get through some of their difficult times.”

Many students live in impoverishment and experience multiple life challenges. As a result, some students are frequent visitors to the health office for relatively minor complains that mask deeper reasons for contact with the nurse. Participants realize that students who make frequent health office visits sometimes are signaling deeper concerns than what may appear on the surface. Creating a "safe haven” for students to express their concerns is said to be a priority for the participants in the study. At times, it may be that the school nurse is the only person in the school who has listened carefully to a 
student's concerns. This allows the school nurse to intervene in specific ways in order to assist students to improve their school experiences. Some of the difficulties students experience are illuminated in Robin's comments:

The kids I work with, they're in survival mode and they come to school with no socks, no underwear, and it's just nice to be able to help them with that, to get ... some of their basic needs [met]....I love having the day-to-day contact with kids and building a good rapport with them....I can be kind of a loving consistent person for them in their lives, because who knows what they are coming from. You know, I can’t fix it all, but at least I can be there a little bit and give them a little hug and say "good morning" to them....

Participants cherish the relationships they build with students and families. These relationships are reciprocal, because students not only receive compassion and kindness from school nurses, but also students, in their responses, often give support to their school nurses. Stella offered an example similar to many related by school nurses:

It seemed like, whenever I was having a bad day, a kid at school [would] say something really nice to me like, “Thank you so much for being here, I’m so glad you're my nurse.” Then I thought well maybe I am doing something to make a difference....

Participants’ child-centered propensities made their day-to-day interactions with students especially meaningful. The opportunities to get to know students as individuals, watch them progress through school, learn of their specific family circumstances so that nurses could provide much needed resources to assist the child were viewed as significant work for nurses. The students’ positive responses to the nurses’ efforts influenced 
participants' view of their jobs. Participants expressed the need to provide assistance to students that improved, in some way, their ability to achieve academically. The confirmation from students that participants were contributing to the creation of a warm, loving, and accepting atmosphere in the school to support students emotionally increased participants' job satisfaction. Candace related:

There are so many positive aspects. And, you know, some seem so menial, but when the kids come in and smile every day and they run up and hug you...I work in an elementary building so their arms are about at my waist and they are just so happy. And whenever they have a problem...one of the first places they come is to the school nurse office. It's a safe haven for them to talk about problems and to receive medical care. And they really know that they can find help in the school nurse's office, so that's always positive....you get positive feedback from the kids.

\section{Challenges}

Nurses in the study identified several encountered challenges that are associated with parents. A primary challenge in this regard is the inability to contact parents in the event of a child's illness, requiring early dismissal from school or other urgent or even emergent situations that may occur. Schools require parents to provide emergency contact numbers in the event that school personnel need to summon parents to the school on behalf of their children. Although the information is important anytime a student needs to leave school due to illness, the emergency contact numbers become critical information in the event that students require urgent or emergency treatment. Betsy 
expressed, in her comments, the frustration of most of the nurses in the study that this lack of adequate emergency contact information can cause:

I think the most challenging aspect [of school nursing] is not having correct addresses and phone numbers. I find that the most frustrating thing [about] being a school nurse, because you have to go through.... litany of phone numbers. And even though you've exhausted all of your options, even the people who are listed [as] the emergency numbers maybe don't have the transportation to come and get a child....then the child has to stay here and literally lay on your cot until someone comes and gets them....

The inability to successfully contact parents who are responsible for providing specific information to the school communicates a disinterest of parents to school nurses and lack of concern for their children's best interests. Participants value their own children and have difficulty developing empathy for parents who seemingly neglect the adequate care of their children when it is clearly needed. Jill aptly commented on this frustration: "It is the parents who just do not seem to want to take care of their kids...." This situation creates problems for participants in their effectiveness at work. Ill children at school are not only in physical discomfort, but may also suffer emotional distress when they cannot access their parents during times of dire need. This is especially significant when they witness other ill children being dismissed from school in the company of their parents. The dilemma is problematic for participants whose desire is to seek appropriate care for students. Parental neglect expands into other aspects of health care that may not involve acute illnesses. Rose further elaborated this notion: 
You begin a process, whether it’s a [health] referral or whatever, and you can only go so far, you know, and that's probably the biggest frustration whether it's [a] mental health or immunization referral, that kind of thing. You just can't walk them [parents] all the way to the end....It really is the responsibility of the family or the guardians, whoever takes care of them [the children] to complete that task. Even when participants have successfully reached parents, communication also can be problematic at times when parents deny the validity of the nurse's observations of a student's condition. Participants possess professional nurse acumen that should be acknowledged by parents for the well-being of students. The diagnostic, nursing observations of school nurses are the results of combined education and experience. Charlotte offered details of a particular incident:

I had a boy last week who injured his thumb at home. His thumb was very swollen and needed to be evaluated by a medical doctor. The dad looked at it and was just like, “Oh, it’s just soap.” I tried to explain to him that it very well could be fractured, but, you know, we needed an x-ray to make sure. He just couldn't understand... why we couldn't just leave it alone... it was fine and he could bend it, you know, and why he had to go to the doctor. So, I think that's the most frustrating aspect is trying to get parents to step up and do what they need to do for their kids....

The majority of nurse participants also are parents and their perspectives on the proper care of children is evident in their approach to the care of the students that they serve in their schools. The stated goal of many participants is to provide the same care to students that they would want provided for their own children if they were in need at 
school. In this way, participants sometimes become a type of surrogate mother to school children. Given this context, the study's nurses experience difficulty in understanding the actions of parents who seemingly neglect their children at critical times. Stella stated the view of many participants:

I would say the most challenging is dealing with some parents [and] dealing with the fact that parents don't treat their kids the way I treat my kids or the way I think they should treat their kids, [by] not providing the basics, especially when there are so many resources available. And when you hook them up with some of the resources and give them coupons for free things that they don't use...that's the most challenging...trying to figure out a way to not enable the parents, but to empower them and to make them accountable.

The lack of cooperation shown by some parents to partner with nurses for the sake of their children who have obvious health care needs was a major professional obstacle expressed by the participants in the study. Mira reflected: “ It can be hard sometimes to convince parents that their child needs services and that this is really about the child and not about me harassing and getting on someone's nerves, so that is challenging sometimes....”

\section{Success Definitions}

Success definitions reported by the participants were relative to the success of the participants in obtaining necessary care for students, including various types of health care and also protective services. In the large urban school district in which participants are employed, many students are in need of vision care. Academic achievement for 
students may be influenced by successful intervention regarding vision problems. For example, Sylvia shared:

I think sometimes our accomplishments are...not big. I mean, we cannot go in and change the dynamics of a family. Sometimes our rewards are small. For instance...getting a child a pair of glasses and maybe for the first time they can see clearly across the parking lot and just watching their response to that.

School nurses sense pressure to accomplish many tasks in the course of a school year. Attempting to meet the salient needs of many students who comprise the school's student population is difficult. There exist many children who have a variety of health needs. School nurses generally, but especially those nurses who have multiple school assignments, have daunting tasks in accomplishing their work within an academic year. There are so many areas of need within schools that the sense of success for school nurses may seem elusive. Lois expanded on what it means to be successful in her work in this way:

Getting the majority of the things that I need to get accomplished...the mandatory physical assessments [health screenings] to make sure that the kids that are there can see and hear, and so getting those done, kind of gives me a measure of success. And not only that, I'm not so focused on those things that I can't do other things that kids present in my office with. Like...there was a little girl who has a tooth that is rotted all the way to her gums. I keep sending a referral to her mom and she keeps coming back to me and I just have to put some of the things that need to be done, like the assessments, on the back burner and I see that I'm going to have to help her get this cavity fixed. So that is success to me, getting 
the majority of the things that need to be done that are required of me to be done and also still attending to [the] everyday needs of the students.

Success also was defined as protecting students from harm. School nurses are legally mandated to report suspected incidences of neglect or abuse of school children to authorities. Sylvia illustrated: "Unfortunately, sometimes helping to get a child removed from a very bad home life into some type of care that is away from the family that truly abuses or neglects him or her....” But this type of success can have difficult consequences for school nurses. Participants view, as a priority, the rapport they develop with their students. Difficult circumstances, such as those arising with child abuse cases, can jeopardize the trusting relationship established between students and their school nurses. Often students do not understand that some confidential matters must be shared with appropriate authorities for the safety of the student. Robin shared her experience: It is disappointing and it's difficult to deal with some of the child abuse cases. It's just emotionally challenging. I have a situation currently that, you know, the student has come...I mean, he has had huge bruises and marks and everything and I called Children's Services.... and they took the child out of the house....It's really difficult, because this kid doesn't want to talk to me, he doesn't like me anymore, and I understand everything about that, but it’s just difficult. So I don’t know. It's a mixed bag sometimes.

Despite the potential repercussions in participants' relationships with students when school nurses must report suspected neglect and abuse cases, participants identified interventions to protect children from harm as a measure of success in their jobs. The 
fractured relationships that these interventions may cause have emotional consequences for participants, but the safety and well-being of students is the greater priority.

Participants also identified successful accomplishments in their jobs when they provide health-related resources for children in need. Ashley summarized the consensus of participants in her statement:

I would probably define success as reaching as many children as possible, advocating for children, trying to keep the children in school, trying to help as many kids [as possible] receive the appropriate medical, dental and vision care that they can...just keeping the students as healthy as [I] can.

Participants related that they expedite student's access of dental, medical, and vision care through collaboration with community agencies that provide these services specifically to underserved school-aged children. Some of these health related resources are made available at specific times during the school year within school buildings or on school property in mobile units or vans. Participants identify students in need of these services and obtain parental consent for some students to receive care during the school day.

Participants concurred regarding the characteristics that nurses should possess in order to have success in school nursing. Patience, a non-judgmental attitude, empathy, and flexibility were salient characteristics. These qualities are some of the ones most identified as appropriate for nurses in all areas of practice. The study's participants reported the need for possessing these characteristics, because they encounter students and families from a variety of cultural backgrounds, socio-economic statuses, and traditions that differ from the participants' own backgrounds. In particular, the participants' collective cultural backgrounds lack the variety represented in the student 
populations that they serve. In order to effectively meet the health care needs of students, participants indicated that they must not view their school families from the participants' own cultural lens, but must identify the values held by students and their families. For example, Robin indicated: "I think they [school nurses] have to like kids, first and foremost... and [have] patience, endurance, and I think being able to work with all different types of people, you know, which goes with most of our nursing profession.” The ability to understand others and an empathic nature were discussed by participants as important school nurse traits. These traits are crucial in developing positive relationships with students and families from the various ethnic and cultural backgrounds represented in the participants' urban school district. Some families may be new, not only to the school district, but also to the country and may also have language barriers. Communicating empathy to immigrant families is essential in assisting students to successfully adjust to American culture. Lois explained some of the steps she follows: Whatever school that I usually am assigned to, I usually try to familiarize myself with that community. When I first started, I would go to aerobics at the recreation center that was in that community. I would just try to familiarize myself with the community so that I could know what types of environments the kids were coming from so that I could better understand... when they came to my office and didn't have socks or undergarments, I could understand what...was going on and not just get mad at the mom or dad for [allowing] them [to] come to school with no socks or underwear.... 
Integration of work and home life

The participants in the sample reported that school nursing provides successful integration of professional and personal lives. An important factor helping to make this true involves the nurses' work schedules. Hospital organizations are known to employ the greatest number of nurses, when compared to other employers. Hospital nursing involves work shifts that must encompass 24 hours of every day. As such, individual nurses often must work during hours that are not ideal with regards to their family requirements. This situation can place stress on nurses who must provide alternative care for their children while they are employed. The occasional required overtime hours may be especially problematic when it occurs without due prior notice. The nursing practice of working 12 hour shifts can have disadvantages that significantly limit the time nurses can spend with their children. Therefore, the school nurse work schedule is significant, not only for the on-duty hours, but also for the off-duty hours. Elizabeth clarified:

I do enjoy the fact that I have summers off. I have to be honest, it’s something that... was part of the purpose that I had and I do appreciate that time with my family and I appreciate my job more knowing that it gives me that time.

Most of the nurses in the study also were parents. Those participants with schoolaged children particularly noted a point of compatibility in school nursing that is mainly attributed to the work schedule. The nurses and their children are away from home during the same hours — those hours that essentially comprise the school day. This arrangement was viewed as a considerable asset. Ashley stated pointedly: "I think school nursing integrates very well with my home life, because I do still have children 
who are in school, so it kind of all blends together...” Emma added the dynamic of dual-income working families:

My husband is in the education system....We have the same schedules. Our kids are in school so our schedule matches them for the most part. But prior to school nursing, I worked every week-end in the hospital since my son was born so at that time it was about ten years so we were on opposite schedules. So this [school nursing] integrates very well with the family.

Due to its predictability, the work schedule permits nurses to make personal plans for off-duty time. This is in contrast to hospital nursing in which overtime work often is expected and may be required, even with short prior notice. Creating alternative arrangements for child care or other personal plans when nurses expect to end their workdays at specific times may be challenging. Jill remarked, regarding the school nurse schedule: “The days ahead are scheduled. You know when you can make airline plans...the school schedule is given ahead of time.”

\section{Summary of Findings}

In sum, the factors that contributed to the selection of school nursing by the nurses in the sample were pediatric nursing, a family-friendly work schedule, and previous observation of school nurses in the work setting. The participants identified the first year of school nursing as the time of the lowest levels of job satisfaction they had experienced in their school nursing career. Data indicated that the perceptions held by participants prior to obtaining a school nurse position and the perceptions they later developed were incongruent. Participants recognized that school nursing has a wider scope of practice than they initially perceived it. Participants transitioned from a narrow 
perception of the school nurse's role (provider of first aid) to the realization that there exist many diverse and significant facets of the specialty. As they gained experience in school nursing, the job satisfaction levels reported by nurses increased.

School nursing is viewed by participants of the study as having many positive aspects that outweigh the challenges. The positive aspects were related to successful interactions with students and the positive feedback nurses received from students that validated the nurses' efforts. Nurses' perceptions that they were making significant contributions to the betterment of students were major positive factors. Challenges largely were identified as the perceived neglect and lack of cooperation of certain parents regarding the care of their children. Difficulty in locating parents when necessary for the care of their children and the occasional disregard by parents of the school nurses' recommendations for health referrals were viewed as particularly problematic for participants. These difficulties were perceived by nurses as a general neglect and lack of concern on the part of parents for their own children. The participants' experiences as parents and their devotion to their own children seemingly influenced the nurses' perceptions of school parents. The failure of parents to avail themselves of the free resources that have potential benefit for their families, especially their children, was an area of specified frustration for nurses in the study.

A successful school nurse embodies characteristics of empathy and caring, flexibility, and a non-judgmental attitude. These characteristics generally are perceived as nursing characteristics across the spectrum of nurse employment. Success is defined through the accomplishments of nurses in accessing necessary services for students in the areas of dental, vision, and medical care. Thus participants are contributing to the 
potential academic success of students by assisting in removing or ameliorating health related obstacles to educational achievement. To secure care for students, participants indicated that nurses strive to do whatever is necessary to improve the well-being of students. 


\section{Chapter 5}

Discussion and Implications

The characteristics of any given school population varies with each school. School nurses must adapt their practice to meet the specific needs of their particular population of students (Oda, 1991). The participants in the present study are employed in a large urban public school district with a student population that represents a variety of ethnic cultures. Many students are from families of low socioeconomic status. These factors may have influenced the perspectives of school nurses regarding their positions. Interpretation of the findings

The present study provides a holistic view of school nursing, because this study utilized participants who are equipped to provide the most credible perspective-school nurses who regularly confront the complexities of the profession. Studies of school nursing and health services in schools often have focused on the perspectives of stakeholders who are not school nurses such as parents, students, educators, school administrators and others who have vested interests in the health concerns of students (Clark, Clasen, Stolfi, \& Jaballas, 2002; Francis, Hemmat, Treloar, \& Yarandi, 1996). Studies such as these emphasize the work of the school nurse rather than the perspectives school nurses possess of their careers. Consequently, a fragmented view of school nursing has ensued among some stakeholders.

The present data show that participants primarily were introduced to school nursing through contact with currently employed school nurses. Consequently, these individuals have the potential to recruit new nurses to the practice of school nursing by positive interactions with nursing students. The influential power of currently employed 
school nurses' satisfaction in their work should not be underestimated. In interacting with nursing students, school nurses have the opportunity to educate them by dispelling myths surrounding contemporary school nurse practice. Participants described their previous contacts with school nurses as consisting of two types: friends who were satisfied with school nursing and school nurses who served as preceptors for students in a baccalaureate nursing program during a public health or community health clinical rotation. These contacts with nurses to the specialty of school nursing were memorable and positive, so that after the nurses in the present study pursued other nurse specialty areas in hospitals or community nursing for several years, they reconsidered school nursing. The investment of time and money to obtain school nurse licensure by the state indicates a substantial commitment to school nurse employment.

The study's findings also indicate that the research participants possess a child and family-centered life perspective. This outlook also is exemplified in their personal lives with respect to their families. Among the factors participants listed as significantly influencing their decision to enter school nursing was the job description's work schedule. The ability of school nurses to spend time with their families, particularly their children, was a high priority in the selection of a school nurse position. This theme was supported in the findings of Thurtle (1996) in the British study of school nurses. Thurtle's ethnographic study investigated the validity of the stereotype of school nursing as a convenient, part-time occupation chosen by nurses, because it is compatible with domestic and childcare responsibilities. This was found to be an accurate stereotype, but not necessarily a negative one. In addition, school nurses in Thurtle’s study perceived their status as being not only lower than nurses who worked in other community settings, 
but also not equitable with teachers. Conversely, the present study primarily involved school nurses who work full-time. Most of them are members of the teachers' bargaining union. The education and salary scale of the participants is comparable to the education requirements and salary scale of school district's educators.

Participants in the study initially thought school nursing entailed basic first aid or "light" nursing. This is consistent with the stereotype that nurses in other specialties are not knowledgeable regarding the practice of school nursing. The finding supported the view in other literature that the majority of people external to school nurse practice have similarly erroneous views of school nursing (Oda, 1991). It was only when nurses obtained school nurse positions that their perspectives on school nursing changed as they adapted to the requirements of the role. Participants in the present study recounted that this adaptation phase was difficult and they perceived it as a potential threat to selfefficacy in the role.

The findings clearly revealed that the initial years of school nursing are difficult. The multitasking activities of school nurses that are deemed necessary to care for students, staff, and parents/guardians are challenges for novice school nurses who are beginning to acclimate themselves to the school nurse specialty. Learning to set appropriate priorities in caring for students, while also learning the system of the schools can be daunting tasks.

The cultural differences between the school nurse and the students in the school system can be difficult to bridge. Working in a large urban public school district in which poverty is a significant and harsh reality in many families' lives also can be a revelation to many school nurses. As advocates for children, school nurses found 
parental neglect, in its various manifestations, a serious challenge to school nurse interventions. Most nurses also were unprepared for the reality of the impact poverty has on families. While nurses realized the necessity of being non-judgmental regarding the values apparent in the behavior of students' families, nurses experienced challenges in adapting to the culture of poverty. Payne (2005) advocates that families in poverty possess perspectives toward life that are substantially different from middle or upperclass families. This perspective influences their values, decisions, and behaviors. A level of understanding must be bridged between school nurses and other school personnel regarding the characteristics of families in poverty and the best means to engage families in the care and educational achievements of their children. The participants' nurturing and caring characteristics undoubtedly impacted their distress in witnessing parental behaviors that they did not understand and previously had not encountered.

Changes in nurses' views, before and after the acquisition of a school nurse position, had an overall impact on job satisfaction. Nurses described their current levels of job satisfaction as being different than they were upon entry into the school nurse position. Specifically, these levels were reported as having been lower within the first one to two years, when compared to current job satisfaction levels. Overall, however, participants described relatively high current levels of job satisfaction. This would suggest that they have made successful transitions to school nursing (Harvey, 1998). The greatest threat to job satisfaction, according to the data, occurs during the first year of school nursing. Participants related comparatively incongruent expectations of the job before and after obtaining a school nurse position. School nurses also were pressured by the disparity in the perception of the school nurse role by other staff and the actual 
requirements as determined, in part, by nurse administrators. This undoubtedly had negative ramifications on initial job satisfaction levels.

\section{Potential applications of the findings}

School nurse programs should include designs that enhance the preparation of nurses by incorporating the study of families in poverty as well as the study of ethnic populations. There is a significant likelihood that school nurses will interact with families in poverty whether these families reside in urban or rural areas. In large cities, families who represent a range of ethnic cultures are also present in schools. This additional education would better prepare school nurses in understanding these families and in devising effective means to holistically assist such families. Thus, school nurses can indirectly support student achievement by addressing basic needs apparent in urban students.

Houghton (2004) emphasized the importance of mentoring programs for new

school nurses. Novice school nurses require the support and validation of veteran school nurses who can assist them in developing time management skills, flexibility, and techniques of efficiency that veteran nurses have experientially learned on the job. In this way, role strain can be diminished and job satisfaction can be increased during this critical time of adjustment. Veteran nurses also can assist novice school nurses in developing greater autonomy which is a valued characteristic of school nursing.

\section{Biblical integration}

The school nurse's compassion for children is imitative of Jesus' compassion for the poor, the sick, orphans, and others who are among the marginalized people in the Bible. For some nurses, school nursing is a "calling." They have a sense of being where 
they are supposed to be and doing what they are supposed to do. Prater and McEwen (2006) posit that a calling can occur in one of two ways: A clear calling from God, as Florence Nightingale, nursing founder, stated she received, or a subtle calling manifested by a series of steps leading to an increasing awareness to the one who is called that this is part of a Divine purpose. As the researcher of the present study and also a school nurse who is a Christian, I believe that each school child is an image-bearer of God (Genesis 1:26). As such, each student has ascribed value that is not predicated on socioeconomic status or academic achievement. It is my hope that students I serve will sense by my actions that I love and value them.

Strengths of the study

The present study is a unique addition to the school nurse literature. There is paucity in school nursing literature regarding what school nurses value and how their values influence their vocational choice. Much of the existing literature focuses on students’ health issues such as asthma (e.g., Anderson, et al. 2005; Major, Clarke, Cardenas, Taylor-Fishwick, Kelly, \& Butterfoss, 2006), diabetes (Nabors, Troillett, Nash, \& Masiulis, 2005; Darby, 2006), and mental health conditions (DeSocio \& Hootman, 2004). There were no studies located in data-base searches in the research literature involving qualitative study designs in the United States that focused on reasons nurses chose school nursing as a professional nurse specialty. The impending nurse shortage crisis will inevitably impact school children. More professional school nurses are necessary for the provision of health care services for students with complex health conditions. Case law has established the responsibilities of school personnel in providing a free and appropriate public school education regardless of the cost and complexity of 
the students' health status. Attracting nurses to school nursing and retaining school nurses in their positions are salient issues for schools. Schools are responsible for providing a safe environment for all students. A safe environment encompasses the expectation that students' health conditions, some of which may be potentially lifethreatening, will be appropriately monitored and interventions performed as necessary. This is best expedited by professional school nurses and is the recommendation supported by the largest school nurse organization, the National Association of School Nurses (NASN, 2002).

\section{Limitations of the study}

The study may not be generalizable to all national school districts for three main reasons. First, variations in school nurse qualifications including education and work experiences limit the external validity of the study. Second, the differences between rural, urban, private, and parochial school districts and the demographic characteristics of their respective student populations, also are delimiting factors. Finally, other characteristics not accounted for in differences in education and work experiences of school nurses who serve in private or parochial schools may limit the study's findings. Consequently, as with most qualitative research, external validity is a salient limitation of the present research study.

Remaining threats to internal validity

The wide range in years of school district employment among nurse participants was a potential threat to internal validity. Although attempts were made to narrow the range of continuous school district employment to create as homogeneous a sample as possible, further narrowing was not possible without sacrificing other criteria of the study 
such as type of degree earned by the participants. Many nurses in the population from which the sample was obtained possess advanced degrees. It was believed that their perspectives might vary from the perspectives of nurses with BSN degrees, making the emergence of themes problematic. A school nurse sample with advanced degrees would make an apt additional study. Since two of the school nurses approached for the study did not agree to be interviewed, this fact may have impact due to self-selecting biases. Also, using the criterion of school enrollment figures in elementary school assignments was not possible, because enrollments between elementary schools varied significantly.

\section{Suggestions for future research}

A similar study involving school nurses with mainly middle school or high school assignments could be conducted with the results compared to the present one. The specific issues of students in middle school and high school may have impact on school nurses’ perspectives in these settings. Any similarities or differences could be compared with the present study.

Additionally, this study could be replicated using private and parochial school nurses to compare similarities and differences in the findings. The study also could be replicated to compare minority samples vs. non-minority samples. Qualitative studies also could be conducted on a larger sample of school nurses as well as replication studies with school nurses employed in districts in different parts of the country with differing student demographics. Additionally, longitudinal studies potentially could offer interesting perspectives of school nurses over longer time frames. Finally, survey research, as a follow-up, could enhance findings of qualitative research studies to provide a more complete view of school nurses’ perspectives. 


\section{Appendix A}

Interview Questions:

1. What factors significantly influenced your decision to enter school nursing?

2. Prior to obtaining a school nurse position, what did you envision the job would entail?

3. Were there various points when you considered quitting? What kept you going?

4. How have your views on school nursing changed since you first chose to enter this nursing specialty?

5. What are the particularly positive aspects of school nursing?

6. What are the special challenging aspects of school nursing?

7. What characteristics do you think a nurse should possess in order to be successful in school nursing?

8. How would you define success in school nursing?

9. Describe your past and present levels of job satisfaction as a school nurse.

10. Describe how your work life as a school nurse integrates with your home life. 
Appendix B

Demographic Data

Age:

Race:

Gender:

From what type of nursing program did you graduate?

Highest degree(s) held:

Non-nursing degree(s)

Years employed in nursing:

a. school nursing

b. non-school nursing

Membership in professional organizations:

COASN

OASN

NASN

CEA

Other? 
Graph

\section{School Nurses}

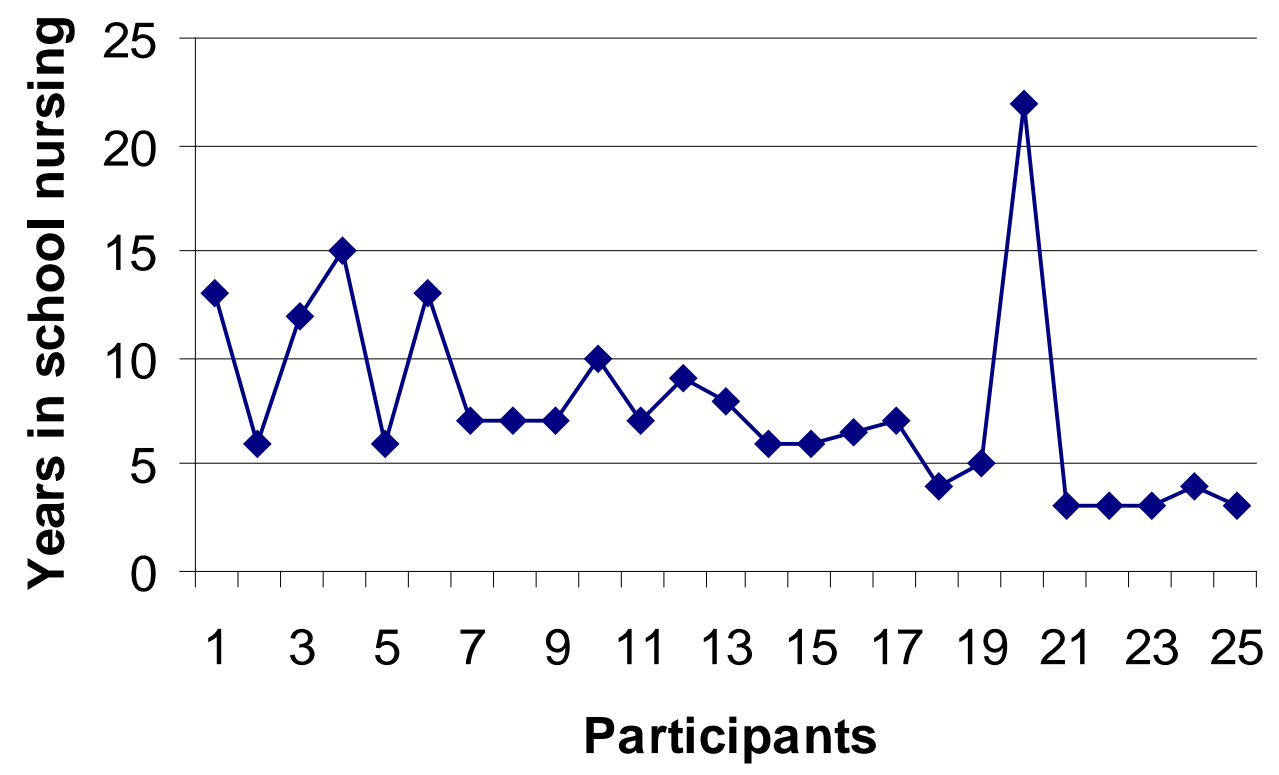

Mean: $7.7 \quad$ Median: $7 \quad$ Mode: 7 
Table

\begin{tabular}{|l|l|l|l|l|l|l|l|l|l|l|l|l|l|l|l|l|l|l|l|l|l|l|l|l|l|} 
Participants & 1 & 2 & 3 & 4 & 5 & 6 & 7 & 8 & 9 & 10 & 11 & 12 & 13 & 14 & 15 & 16 & 17 & 18 & 19 & 20 & 21 & 22 & 23 & 24 & 25 \\
\hline
\end{tabular} Years in
School

Nursing 


\section{References}

Allen, G. (2003). The impact of elementary school nurses on student attendance. Journal of School Nursing, 19, 225-231.

American Academy of Pediatrics Committee on School Health. (1990). Guidelines for urgent care in school. Pediatrics, 86, 999-1000.

American Academy of Pediatrics Committee on School Health. (2001). The role of the school nurse in providing school health services. Pediatrics, 108, 1231-1232.

Anderson, E., Valerio, M., Liu, M., Benet, D., Joseph, C., Brown, R., Clark, N., (2005). Schools’ capacity to help low-income, minority children to manage asthma. The Journal of School Nursing, 21, 236-242.

Beck, C. (2000). The experience of choosing nursing as a career. Journal of Nursing Education, 39, 320-322.

Bierschbach, J., Cooper, L. \& Liedl, J. (2004). Insulin pumps: What every school nurse needs to know. The Journal of School Nursing, 20, 117-123.

Bigby, L. (2004). Medical and health-related services: More than treating boo-boos and ouchies. Intervention in School and Clinic, 39, 233-235.

Bradley, B. (1997). The school nurse as health educator. Journal of School Health, 67, 3-8.

Bradley, L. (2005). School Law for Public, Private, and Parochial Educators. Ann Arbor: Xan Education. 
Bridges, J. (1990). Literature review on the images of the nurse and nursing in the media. Journal of Advanced Nursing, 15, 850-854.

Broussard, L. (2004). School nursing: not just band-aids any more! Journal for Specialists, 9, 77-83.

Buhler-Wilkerson, K. (1993). Bringing care to the people: Lillian Wald's legacy to public health nursing. American Journal of Public Health, 83, 1778-1786.

Bullough, B. (1976). The Law and the expanding nursing role. American Journal of Public Health, 66, 249-254.

Buerhaus, P., Donelan, K., Ulrich, B., \& Dittus, R. (2005). Is the shortage of hospital registered nurses getting better or worse? Findings from two recent national surveys of RNs. Nursing Economic\$, 23, 61-96.

Cedar Rapids Community School District v. Garrett F., 526 U.S. 66 (1998).

Constante, C. (2001). School health nursing: framework for the future, part I. Journal of School Nursing, 17, 3-11.

Constante, C. (2002). State certification for school nurses. Journal of School Nursing, 18, 102-116.

Clark, D.,Clasen, C., Stolfi, A. \& Jaballas, E. (2002). Parent knowledge and opinions of school health services in an urban public school system. Journal of School Health, 72, 18-22.

DeSocio, J. \& Hootman, J. (2004). Children's mental health and school success. The Journal of School Nursing, 20, 189-196.

Dock, L. (1902). School-nurse experiment in New York. American Journal of Nursing, 2, 108-110. 
Dorland, W. (Ed.). (2003). Dorland's illustrated medical dictionary (30 ${ }^{\text {th }}$ ed.) Philadelphia: W.B. Saunders and Company.

Esperat, C., Moss, P., Roberts, K., Kerr, L., \& Green, A. (1999). Special needs children in the public schools: perceptions of school nurses and school teachers. Issues in Comprehensive Pediatric Nursing, 22, 167-182.

Firmin, M. (2006). Using interview waves in qualitative phenomenological research. In P. Brewer \& M. Firmin (Eds.). Ethnographic \& qualitative research in education (pp. 175-181). New Castle, UK: Cambridge Scholars Press.

Foley, M., Lee, J., Wilson, L., Cureton, V., \& Canham, D. (2004). Multi-factor analysis of job satisfaction among school nurses. Journal of School Nursing, 20, 94-100.

Francis, E., Hemmat, J., Treloar, D., \& Yarandi, H. (1996). Who dispenses pharmaceuticals to children at school? Journal of School Health, 66, 355-358.

Furnham, A. (2001). Vocational preference and p-o fit: reflections on Holland's theory of vocational choice. Applied Psychology: An International Review, 50, 5-29.

Gelfman, M. \& Schwab, N. (2000). School health services after Cedar Rapids Independent School District v. Garret F. The Journal of School Nursing, 16, 5459.

Glaser, B. \& Strauss, A. (1967). The constant comparative method of qualitative analysis. In B. Glaser \& A. Strauss (Eds.). The discovery of grounded theory: Strategies for qualitative research (pp.101-114). Chicago: Aldine Publishing Company.

Gordon, S. (2004). Nurses and public communication: protecting definitional claims. Journal of Nursing Management, 12, 273-278. 
Gorlick, H. (1967). Are school nurses first-aiders or health-leaders? RN, 53-58, 101.

Grant, A. (2001). The nurse in the school health service. Journal of School Health, 71, 388-389.

Gregory, E. (2006). Federal laws protecting children and youth with disabilities. In J. Selekman, (Ed.). (2006). School nursing; A comprehensive text. (pp. 301-319). Philadelphia: F. A. Davis.

Guilday, P. (2000). School nursing practice today: implications for the future. Jounal of School Nursing, 16, 25-31

Guttu, M., Engelke, M., \& Swanson, M. (2004). Does the school nurse-to-student ratio make a difference? Journal of School Health, 74, 6-9.

Harris, G. (2006). Taking it to the next level. Retrieved September 15, 2006 from, http://www.columbus.k12.oh.us/website.nsf/D185095EA0B36AF7852571CC006 F92F7/\$File/081606\%20Metropolitan\%20Club\%20Speech\%20_August\%202006 _.pdf?OpenElement

Harvey, G. (1998). Making the transition from acute care to school nursing. Journal of School Nursing, 14, 40-46.

Hawkins, J., Hayes, E., \& Corliss, P. (1994). School nursing in America-1902-1994: A return to public health nursing. Public Health Nursing, 11, 416-425.

Hitti, M. (2004, December 8), Nurses top list for honesty. Message posted to news: http://www.cbsnews.com/stories/2004/12/08/health/webmd/main659857.shtml

Holland, J. (1959). A theory of vocational choice. Journal of Counseling Psychology, 6, $35-45$. 
Hootman, J. (1994). Nursing our most valuable natural resource: school age children. Nursing Forum, 29, 5-17.

Hootman, J., Houck, G., \& King, M. (2003). Increased mental health needs and new roles in school communities. Journal of Child and Adolescent Psychiatric Nursing, 16, 93-101.

Houghton, C. (2003). A mentoring program for new school nurses. The Journal of School Nursing, 19, 24-29.

Johnson, B., \& Christensen, L. (2004). Methods of data collection. In B. Johnson \& L. Christensen (Eds.).Educational research quantitative, qualitative, and mixed approaches (pp.161-195). Boston: Pearson.

Johnson, R., Johnson, J., \& Johnson, E. (2005). Discover nursing. Retrieved December 6, 2006 from, http://www.discovernursing.com/nursing-careers

Johnson, J. (2004). No (sick) child left behind. Revolution, 5, 24-31.

Junious, D., Johnson, R., Peters, R., Markham, C., Kelder, S., Yacoubian, G. (2004). A study of school nurse job satisfaction. The Journal of School Nursing, 20, 88-93.

Kalisch, P. \& Kalisch, B. (1982). The image of the nurse in motion pictures. American Journal of Nursing, 4, 605-611.

Keddy, B., Gillis, M., Jacobs, P., Burton, H., \& Rogers, M. (1986). The doctor-nurse relationship: an historical perspective. Journal of Advanced Nursing, 11, 745-753.

Kanter, R. (2000). Power failure in management circuits. Harvard Business Review, 57, 65-75.

Keller, T. (2004). A differentiated practice model for school nursing. The Journal of School Nursing, 20, 249-256. 
Kelsey, A. (2002). Health care for all children: the beginnings of school nursing 19041908. International History of Nursing Journal, 7, 4-11.

Kort, M. (1984). The delivery of primary health care in American public schools, 18901980. Journal of School Health, 54, 453-457.

Legislative Office of Education Oversight. (2002). Ohio Students Identified as "Other Health Handicapped". Columbus, Ohio: Author. Retrieved 11/30/06 from http://www.loeo.state.oh.us/reports/PreEleSecPDF/Other\%20Health\%20Handicap ped.pdf

Lear, J. (2006). Children's health and children's schools: A collaborative approach to strengthening children’s well-being. In J. Lear, S. Isaacs, \& J. Knickman (Eds.). School health services and program (pp.3-38). San Francisco: Jossey-Bass.

Likoff, L., Romanosky, N. (Eds.) (2005). Encyclopedia of careers and vocational Guidance (13 ${ }^{\text {th }}$ ed., vol. 5). New York: Ferguson Publishing Company. Macdonough, G. (2001). Comparison of nursing roles. Journal of School Health, 71, 407.

Major, D., Clarke, S., Cardenas, R., Taylor-Fishwick, J., Kelly, C., \& Butterfoss, F. (2006). Family \& Community Health, 29, 256-265.

Maughan, E. (2003). The impact of school nursing on school performance: a research Synthesis. Journal of School Nursing, 19, 163-171.

Meier, E. (1999). The image of a nurse—myth vs. reality. Nursing Economic\$, 17, 273-275.

Munoz-Furlong, A. (Ed.). (1995). The school food allergy program. (Rev. ed.). Fairfax, Virginia: The Food Allergy Network. 
Munoz-Furlong, A. (2006). Going nuts over allergies. Education Digest, 71, 33-34.

Nabors, L., Troillett, A., Nash, T., \& Masiulis, B. (2005). School nurse perceptions of barriers and supports for children with diabetes. Journal of School Health, 75, $119-124$.

National Association of School Nurses (2005). School nursing scope and standards of practice. Silver Spring: Nursebooks.

National Association of School Nurses (2006). School nursing management of students with chronic health conditions. Retrieved September 3, 2007, from http://www.nasn.org/Portals/0/briefs/2006briefchronichealth.pdf

National Association of School Nurses (2002). Position statement. Education, Licensure, and certification of school nurses. Retrieved December 4, 2006, from http://www.nasn.org/Default.aspx?tabid=219

Oda, D. (1979). School nursing: current observations and future projections. The Journal of School Health, 49, 437-439.

Oda, D. (1991). The invisible nursing practice. Nursing Outlook, 39, 26-29.

Oda, D. (1992). Is school nursing really the “invisible practice?” Journal of School Health, 62, 112-113.

Payne, R. (2005). Definitions and resources. In R. Payne (Ed.). A framework for understanding poverty (pp. 16-39). Highlands, Texas: Aha! Process.

Prater, L. \& McEwen, M., (2006). Called to nursing. Journal of Holistic Nursing, 24, 63-69.

Percy, M. (2006). Welcome to school health. Journal for Specialists in Pediatric Nursing, 11, 149-152. 
Regan, P. (1976). A historical study of the school nurse role. The Journal of School Health, 46, 518-521.

Rehm, R. (2002). Creating a context of safety and achievement at school for children who are medically fragile/technology dependent. Advances in Nursing Science, 24, 71-84.

Rogers, L. (1908). Some phases of school nursing. American Journal of Nursing, 8, 966974.

School nurse and teacher too. (1969). $R N, 32,46-49$.

Seago, J. (2006). The nursing shortage: is it really about image? Journal of Healthcare Management, 51, 96-108.

Selekman, J., \& Guilday, P. (2003). Identification of desired outcomes for school nursing practice. Journal of School Nursing, 19, 344-350.

Simmons, D. (2002). Autonomy in practice: A qualitative study of school nurses' perceptions. The Journal of School Nursing, 18, 87-94.

Silver, H. (1980). The school nurse practitioner. Pediatrics, 65, 641-643.

Smith, J. (2004). Marginalization and school nursing. The Journal of School Nursing, 20, 311-316.

Solum, L. (2003). Ethical problems experienced by school nurses. The Journal of School Nursing, 19, 330-337.

Spring, J. (2001). The great civil rights movement and the new culture wars. In J. Spring (Ed.). The American school 1642-2000 ( $5^{\text {th }}$ ed., pp. 413). New York: McGrawHill. 
Stainbeck, S. \& Stainbeck, W. (1988). Interviewing. In S. Stainbeck \& W. Stainbeck (Eds.).Understanding \& conducting qualitative research (pp.51-53). Dubuque: Kendall/Hunt.

Strauss, A. \& Cordbin, J. (1990). Open coding. In A. Strauss \& J. Corbin (Eds.). Basics of qualitative research (pp.61-74). Newbury Park: Sage Publications.

Takase, M., Maude, P., \& Manias, E. (2005). Nurses’ job dissatisfaction and turnover intention: methodological myths and an alternative approach. Nursing and Health Sciences, 7, 209-217.

Tetuan, T. \& Akagi, C. (2004). The effects of budget, delegation, and other variables on the future of school nursing. The Journal of School Nursing, 20, 352-358.

The College Board Book of Majors ( $2^{\text {nd }}$ ed., 2006). College Board Publications, Plano, TX: Author.

The Princeton Review Guide to College Majors (2007). New York: Random House.

Thurtle, V. (1996). Why nurses choose to enter school nursing. Health Visitor, 69, 231233.

U.S. Department of Labor. (2006). Registered nurses. In Occupational outlook handbook (pp. 303-307). Bernan: Lanham.

U.S. Department of Health and Human Services. (2004). The registered nurse population: national sample survey of registered nurses. Retrieved 10/19/06 from http:bhpr.hrsa.gov/healthworkforce/reports/rnpopulation/preliminaryfindings.htm 
U.S. Department of Health and Human Services. (2002). Projected supply, demand, and shortages of registered nurses: 2000-2020. Retrieved 12/8/06 from http://www.ahca.org/research/rnsupply_demand.pdf

Vessey, J., \& McGowan, K. (2006). A successful public health experiment: school nursing. Pediatric Nursing, 32, 255-213.

Weber, R. (2007). A band-aid solution. Neatoday, 25, 31-33.

What does a school nurse do all day? (1966). $R N, 29,87-89$.

While, A. \& Blackman, C., (1998). Reflections on nursing as a career choice. Journal of Nursing Management, 6, 231-237.

Wilson, C., (2005). Said another way. Nursing Forum, 40, 116-118.

Wolfe, L., \& Selekman, J., (2002). School nurses: what it was and what it is. Pediatric Nursing, 28, 403-407.

Woolley, A. (2004). A retrospective look at the entry dilemma. Nursing Forum, 39, 3336.

Wyman, L. (2005). Comparing the number of ill or injured students who are released early from school by school nursing and nonnursing personnel. The Journal of School Nursing, 21, 350-355.

Zaiger, D. (2000). School nursing services: the early years. The Journal of School Nursing, 16, 11-19.

Zimmerman, B., Wagoner, E., \& Kelly, L. (1996). A study of role ambiguity and role strain among school nurses. The Journal of School Nursing, 12, 12-18. 